\title{
In-Silico analysis and molecular docking studies of phytoconstituents of Justicia adhatoda as potential inhibitors of SARS-CoV2 target proteins
}

\author{
Abhinayaa Ananth Suryanarayana, Soundarya Shankar, Jeevitha Priya Manoharan, \\ Subramanian Vidyalakshmi * \\ \{ abhinayaananth@gmail.com, soundaryashankar2000@gmail.com, jeevithapriya2005@gmail.com, \\ svd.bio@psgtech.ac.in\} \\ Department of Biotechnology, PSG College of Technology, Coimbatore, Tamil Nadu, India.
}

\begin{abstract}
The outbreak of COVID 19, a pandemic disease spread by the novel Coronavirus-SARS- CoV-2 infection, there is an emerging necessity to identify potential and effective therapeutic drug candidates. Many researchers have focused on exploiting the antiviral properties of phytocompounds from traditionally used medicinal plants. Computational prediction of drug candidates has shown prospects in the identification of therapeutic targets of SARS-CoV-2. Our current study explores the possibility of identifying potential anti-COVID candidates from the phytocompounds of Justicia adhatoda by virtual screening. Molecular docking analysis of these lead compounds were performed at the binding pockets of 10 viral proteins. The compounds were analyzed for their ADMET properties, drug-likeness, and bioactivity to examine their druggability. Our findings indicate that $51.5 \%$ of phytocompounds from Justicia adhatoda are druggable against COVID-19. It was also found that the phytocompounds xanthoxylol, podophyllotoxin, quercetin, chinensinaphthol methyl ether, and apigenin could act as potential lead molecules against multiple target proteins of SARS- CoV-2..
\end{abstract}

Keywords: SARS-CoV 2, Justicia adhatoda, Phytocompounds, Molecular docking,ADMET, Anti-COVID drug.

\section{Introduction}

Severe Acute Respiratory Syndrome - Coronavirus - 2 (SARS-CoV-2), which has led to the ongoing Covid-19 pandemic, has posed a serious health threat across the entire globe. The World Health Organization (WHO) has announced 24,257,989 confirmed cases of COVID-19, leading to 827,246 deaths across the globe as on 10 July 2020 (https://covid19.who.int/). Currently, there are no effective drugs or vaccines available to protect us from the virus. Several medicinal plants have been reported to possess anti viral effects on herpes simplex virus type 2 (HSV-2) (Debiaggi et al., 1988), HIV (Asres and Bucar, 2005) and emerging severe acute respiratory syndrome (SARS) virus (Kotwal et al., 2005). Naturally occurring phytocompounds have also been shown to exhibit several pharmacological properties like immunostimulatory properties (Webster et al., 2006), inhibitory effects on viral protease (Mukhtar et al, 2008), and anti-inflammatory properties (Hajjaj et al., 2013). Bioactive compounds from medicinal plants are particularly advantageous due to their ease of 
availability and lesser side effects. Phytocompounds are also preferred than synthetic compounds as repurposing these compounds from plants is less time consuming than developing a new molecule from the scratch. The plant chosen in this work is Justicia adhatoda, which is traditionally used as an expectorant for treating respiratory disorders (Murugesa mudhaliar KS., 2006). Studies have also shown that the extracts of this plant inhibited influenza virus attachment and/or viral replication (Shahid et al., 2013).

Drug discovery is a very challenging process. Of late, exploiting computational tools for novel drug development had shortened the time taken for the drug discovery process and also made the process very efficient. Molecular docking, molecular simulation, and virtual screening are valuable tools for screening potential drugs/molecules from various databases that have enormous data on various compounds (Wadood et al., 2013). One of the crucial steps in in silico drug designing is selecting the drug targets from the pathogen (Eweas et al., 2014). The number of SARS-CoV-2 structures deposited in the RCSB Protein Data Bank is tremendously increasing (RCSB PDB). An extensive literature survey showed that the proteins involved in viral entry (Spike glycoprotein) (Prasanth et al., 2020; Hall and Ji , 2020 ; UNNI et al., 2020) and replication (16 non-structural proteins) (Islam et al., 2020; Sinha et al., 2020; Chikhale et al., 2020; Azim et al., 2020) can be targeted for drug discovery.

Coronovirus has been reported to possess at least six ORFs in its genome. Around 16 NSPs (nsp1-16) constitute about two-thirds of the entire genome length. ORF1a and ORF1b are cleaved to form the two polypeptides: ppla and pplab, which are processed by chymotrypsin- like protease (3CLpro) or main protease (Mpro) and one or two papain-like proteases to generate 16 NSPS. These proteins are generated from the single guide RNAs of CoVs. The structural proteins spike $(\mathrm{S})$, membrane $(\mathrm{M})$, envelope $(\mathrm{E})$, and nucleocapsid $(\mathrm{N})$ proteins are encoded by ORFs 10, 11 (Shaikh et al., 2007). The virus also encode special proteins, including hemagglutinin esterase protein, $3 \mathrm{a} / \mathrm{b}$ protein, and $4 \mathrm{a} / \mathrm{b}$ protein. These proteins are necessary for genome maintenance and virus replication. The spike (S) protein is responsible for the viral entry into target cells, which is dependent on the binding of its surface unit, S1 to a cellular receptor. This further facilitates viral attachment to the target cells. (Hoffmann et al., 2013). NSP 3 and nsp4 are involved in the assembly of virally induced vesicles necessary for viral replication. Nsp3 releases Nsp1, Nsp2, and interacts with other NSPS and RNA to form the replication/transcription complex. Nsp3 also antagonize the host innate immune response. Nsp3 also interact with host proteins (such as RCHY1) to support viral survival (Lei et al., 2018). Nsp9 is involved in the transcription and replication of viral RNAs (Sutton et al., 2004). SARS-CoV has been shown to interact with angiotensinconverting enzyme 2 (ACE2) to initiate its entry into the target cells ( $\mathrm{Li}, 2008$; Kirchdoerfer et al., 2018; Li et al., 2003).

It was shown by Liu wenzhong and Li hualan (2020) that ORF1ab, ORF10, and ORF3a proteins attack heme and dissociate iron to generate porphyrin. This is responsible for the respiratory failure in the host system. Lack of oxygen causes leads to multiple organ failure (Abhrajit and Arijit, 2020). These studies were carefully investigated for choosing the drug targets of SARS-CoV2. Hence, in this analysis, 10 structural and non-structural proteins of SARS-CoV2 were used for identifying potential lead compounds against them.

Our current study aimsin identifying an effective lead molecule against the virus from natural sources. Kabasura kudineer, a Siddha formulation used against fevers leading to respiratory infections showed activity against viral proteins and also modulates the host immune system. Most of the phytocompounds prevented the binding of viral protein with the receptor (Pitchiah Kumar et al., 2020). 
Justicia adhatoda, one of the plants which comprise a major part in the Kabasura kudineer formulation was chosen for screening potential inhibitors against ten of the SARSCoV-2 proteins. Previous studies support the usage of the extract of Justicia adhatoda as a remedy for the patients affected by COVID-19 (Abhrajit and Arijit, 2020; Corrêa et al., 2012). Virtual docking analysis was performed against the target proteins to identify potential lead molecules which might act as inhibitors of COVID-19.

\section{Materials And Methods}

Selection of Ligands:

An exhaustive review of scientific literature was done to screen for the various phytocompounds present in Justicia adhatoda (Thokchom et al., 2011). An extensive library of phytochemicals having 87 active compounds (Supplementary Table 1) was pooled and the library was constructed with 68 molecules. The 3D structure of the 68 phytocompounds (Supplementary Table 2) was retrieved from the PubChem database (https://pubchem.ncbi.nlm.nih.gov/) in SDF format. Compounds lacking structures in any of the databases and literature were neglected for the current study.

Drug likeness properties:

Drug likeness properties of the phytocompounds were computed using SWISS ADME (Daina et al., 2017), an online tool based on Lipinski's rule of five (Ro5). The rule was developed to set drug ability guidelines for new molecular entities and predicts that molecules are more likely to show good absorption when there are less than $5 \mathrm{H}$-bond donors and $10 \mathrm{H}$ bond acceptors, for ligands with a molecular weight lesser than $500 \mathrm{Da}$ and whose calculated Log P is less than 5(Lipinski et al., 2001). Ligands obeying the rule of five were taken for ligand preparation for performing molecular docking studies.

Ligand preparation:

The ligands were prepared to ensure that the atoms in the ligand molecules are assigned to the correct Autodock 4 atom types required to run Autodock VINA simulation. Autodock 4 (AD4) atom types are similar to that of the elements in most atoms except for the replacement of hydrogen-bond acceptors $\mathrm{O}, \mathrm{N}$ and $\mathrm{S}$ atoms with "OA", "NA" and "SA"; hydrogen-bond donor $\mathrm{H}$ atoms with "HD"; non-hydrogen bonding nitrogen with "N" and "A" for carbons in aromatic rings. PDBQT format is identical to PDB format but includes partial charges (Q) and AD4 atom types (T). 35 Ligands obeying the Lipinski rule of five along with 10 FDA approved repurposed COVID 19 drugs (Positive controls) were included for the study and are listed along with their chemical structures in Table 1. The ligands were prepared in AUTODOCK tools by the addition of Gasteiger charges for docking analysis. Further nonpolar hydrogen bonds were merged for the ligands and the file was stored in PDBQT format.

Protein preparation:

The X-ray diffraction-based 3D crystal structures of 10 essential SARS-CoV-2 proteins were downloaded in PDB format from the RCSB PDB (https://www.rcsb.org/) database. An open-source molecular visualization tool: The PyMOL Molecular Graphics System, Version 1.2r3pre, Schrödinger, LLC. was used to clean the proteins by removing the water molecules, ions, and ligands present in the retrieved proteins. All the proteins were energy minimized using the Swiss- PDB Viewer. The Graphical user interface software AUTODOCK tools was used to prepare the protein by deleting het group water molecules. Addition of Kollman 
charges and polar hydrogen bonds were performed and the prepared proteins were stored in PDBQT format for docking analysis.

Active site prediction of the proteins and grid generation:

Active site residues of the target proteins were predicted using METAPOCKET 2.0, an online meta server which is a combination of the following eight methods: LIGSITEcs, PASS, Q- SiteFinder, SURFNET, Fpocket, GHECOM, ConCavity and POCASA for better prediction rates (Huang, 2009). Docking simulations in Autodock Vina 1.1.2 were done by the generation of specific grids around the active site residues reported at the top hit of each protein. The parameters used for grid generation are listed in Table $\mathbf{2}$.

Molecular docking:

Molecular docking is employed to identify the essential amino acid interactions between the selected protein and generated ligands with low energy conformation (Carlesso et al., 2019). Autodock Vina 1.1.2 (Trott and Olson, 2010) was used to perform 10 runs of flexible docking for each protein with the phytocompounds and 10 repurposed COVID drugs individually using AutoDockZN forcefield with the recognized active site placed within the constructed grid. Docking scores were reported in $\mathrm{kcal} / \mathrm{mol}$ and compounds with a threshold value lesser than $-7 \mathrm{kcal} / \mathrm{mol}$ were analyzed further for protein-ligand interaction. Identification of ligand interactions in the protein-ligand complexes reports the critical residues involved in the interaction and nature of their interaction. This study is performed using Protein- Ligand Interaction Profiler (PLIP) (Salentin et al., 2015). Two-dimensional LIGPLOT (Wallaceet al., 1995) representations of receptor-ligand interaction were generated with PDBsum: a pictorial database (http://www.ebi.ac.uk/pdbsum).

ADMET analysis of Phytocompounds:

ADMET analysis was performed for the top scoring ligands (Supplementary Table 3) which reported several pharmacokinetic properties including water solubility, intestinal absorption, CYP inhibition, blood brain barrier permeability, total clearance, maximum recommended tolerated dose and acute rat toxicity dosage. Toxicity profiles of individual phytocompounds were also generated with the pkCSM Biosig online server (Pires et al., 2015). AMES toxicity is predicted to determine if the compound could be mutagenic. On the other hand, hepatotoxicity plays an important safety concern in drug development which may lead to drug attrition and may disrupt the normal function of the liver. Thus, phytocompounds which were negative for both AMES and hepatotoxicity tests were taken forward for ligand interaction studies as these molecules will show no indication of carcinogenicity as well as chemical driven liver damage.

PASS computer program

Prediction of Activity Spectra for Substances (PASS) was determined using the PASS Online tool, a computer-based program providing biological activity, to check the ability of phytocompounds to interact with various biological molecules by predicting probable activity $(\mathrm{Pa})$ and probable inactivity $(\mathrm{Pi})$. The substances possessing a higher $\mathrm{Pa}$ than $\mathrm{Pi}$ are favorable drug molecules (Goel et al., 2011; Khurana et al., 2011). The antiviral activity was predicted for the lead compounds. 


\section{Results And Discussion}

Studies suggest that natural compounds can be used to target several human diseases (Pop et al., 2018). In this context, medicinal plants display themselves as valuable sources of drugs to treat many ailments and infectious diseases. Also, Indian medicinal plants have been used by the traditional Ayurveda, Siddha, and Unani based systems of medicine since several years (https://www.nmpb.nic.in/content/medicinal-plants-fact-sheet). There has been an enormous interest in the screening of phytocompounds as drug source. Plants have been the primary sources of medicine for early drug discovery (Veeresham, 2012). Our current study looks out for anti-COVID compounds from the plant Justicia adhatoda through computational molecular docking and drug prediction studies.

Analysis of drug-likeness properties

A wide range of phytocompounds of $\mathrm{J}$. adhatoda possessing various pharmacological activities such as antimicrobial (Sarker et al., 2009), bronchodilator activity (Dorsch and Wagner, 1991), anti-allergic (Paliwa et al., 2000), anti-asthmatic (Wagner, 1989), antiinflammatory (Chakraborty and Brantner, 2001) and abortifacient (Claeson et al., 2000) have been picked up from literature analysis and a schematic representation of initial screening of compounds is depicted in Figure 1. Drug likeness properties of 68 compounds were assessed by an online server SWISS ADME. 35 phytocompounds were found to obey the Lipinski rule of five criteria. The molecular weight of the selected compounds was within the range of 162 - 414 Da. About $26 \%$ of the screened compounds were found to possess 6 hydrogen bond acceptors. Similarly, $40 \%$ of the filtered compounds were noticed to have zero hydrogen bond donors. A Log P value of the compounds was within the range of $0.4-3.7$, indicating that the compounds were lipophilic in nature. These results show that the phytocompounds selected for our study are likely having good absorption and permeation properties in the biological system and might act as potential drug candidates. Lipinski's rule of five parameters of phytocompounds are listed in Table 3.

Toxicity profiles

The toxicity profiles of the phytocompounds were predicted and summarized in Table 4. The toxicity profile includes ten parameters namely AMES toxicity, maximum tolerated human dose, herG I inhibitor, herG II inhibitor, oral rat acute toxicity, oral rat chronic toxicity, hepatotoxicity, skin sensitization, T. pyriformis toxicity, and minnow toxicity. The analysis predicted that 12 of these phytocompounds (Figure 2) were nontoxic and could be potential drug candidates.

Molecular Docking studies

The 12 nontoxic phytocompounds and 10 FDA approved COVID-19 repurposed drugs were screened against 10 target proteins of coronavirus using Autodock VINA 1.1.2. The docking score of the phytocompounds is represented in $\mathrm{kcal} / \mathrm{mol}$ and summarized in Table $\mathbf{5}$. Thedocking scores of FDA approved drugs is given in Table $\mathbf{6}$. The majority of the phytocompounds showed good docking affinity with the target proteins in the range of -5.9 to $-9.5 \mathrm{kcal} / \mathrm{mol}$. The affinity of the repurposed drugs is in the range of -4.6 to $-10.4 \mathrm{kcal} / \mathrm{mol}$. Figure 3 represents the percentage of phytocompounds with a favorable binding affinity against the target proteins of COVID-19. Nearly 88.57 percentage of the compounds showed a higher binding affinity to the spike protein of coronavirus and therefore these compounds might act as a barrier for attachment of the viral protein with the host cell. From our analysis, it was seen that the most potent inhibitor for the main protease is chinensinaphthol methyl ether $(-8 \mathrm{kcal} / \mathrm{mol})$. This compound also showed the highest binding affinity of $-8.8 \mathrm{kcal} / \mathrm{mol}$ for the spike protein - RBD complex Luteolin binds with the highest affinity to spike protein 
(-9.1 kcal/mol).Among the repurposed drugs, darunavir was found to possess the most favourable docking scores against multipleproteins like envelope protein $(-10.6 \mathrm{kcal} / \mathrm{mol})$, spike protein $(-10.3 \mathrm{kcal} / \mathrm{mol})$ and membrane protein $(-10.2 \mathrm{kcal} / \mathrm{mol})$. It was also observed that a majority of the ligands showed favourable docking interaction with all the target proteins.

A heatmap represented in Figure 4 was generated to indicate the degree of relatedness of the target proteins and the ligands. It can be seen that the target protein bifurcates into two classes. Spike protein, spike protein - RBD complex, and nsp9 are closer in the tree and the other proteins are clustered as a separate class. This indicates that most of the ligands had a similar binding affinity for these proteins. Similarly, the clustering pattern of the ligands is also shown in the generated heat map. It can be observed that the repurposed drug darunavir, which showed the maximum binding affinity with many target proteins, is distantly related to the phytocompounds indicating a different mechanism of action.

Two-dimensional ligand interaction profile

To evaluate the binding interaction of the docked protein-ligand complexes, 2D proteinligand interaction profiling was done for both phytocompounds and FDA approved repurposed drugs (Supplementary Table 4) and the residues involved in hydrogen bond formation and hydrophobic interactions are summarized and represented in Table 7,8 and Figure $\mathbf{5 .}$ Hydrogen bonds are of great importance in protein folding, protein ligand interaction, and catalysis. Quercetin showed the highest number of hydrogen bonds formed with the Spike protein among all the top-scoring ligands with an affinity of $-9.1 \mathrm{kcal} / \mathrm{mol}$. Xanthoxylol on the other hand forms the highest number of hydrophobic interactions with the envelope protein with a docking affinity of $-8.4 \mathrm{kcal} / \mathrm{mol}$ which is essential in increasing the binding affinity between the protein and ligand. As the number of hydrophobic atoms in the active core of the drug-target interface increases the biological activity of the drug also increases, making both xanthoxylol and quercetin highly versatile drug compounds capable of inhibiting most of the target proteins with great affinity. Ligand interactions were also studied for FDA approved repurposed COVID 19 drugs and it was noticed that similar patterns of interactions were observed for xanthoxylol and darunavir forming a hydrogen bond with the residue 26B TYR and hydrophobic interactions with the residues 63B TYR and 235A PRO of membrane protein. Similarly, chinensinaphthol methyl ether and hydroxychloroquine recognized alike interacting residues showing hydrogen bonds with 26A THR, 143A GLY and hydrophobic interactions with $165 \mathrm{~A} \mathrm{MET}$ in the main protease of coronavirus. These results suggest that few of our selected compounds such as chinensinaphthol methyl ether and xanthoxylol were showing greater accordance with the pattern of interactions of currently approved COVID drugs. Therefore, these phytocompounds can be utilized for inhibiting the target proteins of COVID-19 upon experimental validation.

\section{ADMET analysis of lead molecules}

ADMET prediction has a central role in determining the pharmacokinetic properties which is cardinal in any drug development and improve efficiency in eliminating weak candidates in the early stages. In silico methods were employed to predict absorption, distribution, metabolism, excretion, and toxicity of the 12 potential lead molecules passing the AMES and hepatotoxicity tests using the pkCSM approach. The ADME/T profiles of 12 phytocompounds are listed in Table 9. In comparison with the repurposed drugs, the ADMET 
properties of the proposed ligands are at par. The ADMET properties of drug-like molecules demonstrated that the compounds possessed good water solubility and intestinal absorption. The lead molecules chinensinaphthol methyl ether, podophyllotoxin, quercetin, xanthoxylol showed intestinal absorption of $100 \%, 100 \%, 77.207 \%, 94.756 \%$ respectively. Other parameters exhibited satisfactory results as well. Many drugs are deactivated by cytochrome P450 and some are activated by it. Among the 12 lead-like compounds, chinensinaphthol methyl ether, heliobuphthalmin, justiciresinol, podophyllotoxin, vasicilonone and xanthoxylol has the ability to act as CYP450 substrate. Considering the total clearance of these molecules, chinensinaphthol methyl ether has the highest clearance rate of about $0.461 \log \mathrm{ml} / \mathrm{min} / \mathrm{kg}$, the rest of them having acceptable clearance values. The intestinal absorption of lead molecules was more than $30 \%$ indicating that it can be highly absorbed and hence well suited for oral administration. From the other ADMET properties listed, it is suggested that the lead molecules are acceptable for human consumption although in-vivo validation is essential.

PASS profile

The antiviral activity of the lead molecules is assessed by PASS online tool and is summarized in Table 10. The predicted $\mathrm{Pa}$ and $\mathrm{Pi}$ values show that all lead compounds possessed a higher probability to be active against most viruses. Lead molecules, namely kaempferol, xanthoxylol, and quercetin were predicted to possess efficient antiviral activity. These results suggest that the lead molecules can be efficient in fighting against SARS CoV-2 also.

\section{Conclusion}

Considering this global threat of COVID-19 with no proven antiviral agents available for immediate recovery, our findings help in establishing a broader perspective of potential antiviral lead compounds from Justicia adhatoda. Most of the top-scoring ligands possessed remarkable ADME properties, but on narrowing down the ligands based on toxicity and other pharmacological properties, the phytocompounds xanthoxylol, apigenin, chinensinaphthol methyl ether, quercetin, and podophyllotoxin may serve as effective lead candidates to inhibit SARS-CoV2. Further experimental studies should be carried out for identified lead molecules for exploring the mechanism of inhibition against COVID-19.

\section{Disclosure Statement}

There is no potential conflict of interest.

\section{Funding}

There is no funding associated with this work.

\section{References}


[1] Asres, K., \& Bucar, F. (2005). Anti-HIV activity against immunodeficiency virus type 1 (HIV-I) and type II (HIV-II) of compounds isolated from the stem bark of Combretum molle. Ethiopian medical journal, 43(1), 15-20.

[2] Azim, K. F., Ahmed, S. R., Banik, A., Khan, M., Deb, A., \& Somana, S. R. (2020). Screening and druggability analysis of some plant metabolites against SARS-CoV-2: An integrative computational approach. Informatics in medicine unlocked, 20, 100367. https://doi.org/10.1016/j.imu.2020.100367

[3] Bag, A., \& Bag, A.. (2020). Treatment of COVID-19 patients: Justicia adhatoda leaves extract is a strong remedy for COVID-19 - Case report analysis and docking based study (Version 1). ChemRxiv. https://doi.org/10.26434/chemrxiv.12038604.v1

[4] Carlesso, A., Chintha, C., Gorman, A. M., Samali, A., \& Eriksson, L. A. (2019). Merits and pitfalls of conventional and covalent docking in identifying new hydroxyl aryl aldehyde like compounds as human IRE1 inhibitors. Scientific reports, 9(1), 3407. https://doi.org/10.1038/s41598-019-39939-Z

[5] Chakraborty, A., \& Brantner, A. H. (2001). Study of alkaloids from Adhatoda vasica Nees on their antiinflammatory activity. Phytotherapy research : PTR, 15(6), 532-534. https://doi.org/10.1002/ptr.737

[6] Chikhale, R. V., Gurav, S. S., Patil, R. B., Sinha, S. K., Prasad, S. K., Shakya, A., Shrivastava, S. K., Gurav, N. S., \& Prasad, R. S. (2020). Sars-cov-2 host entry and replication inhibitors from Indian ginseng: an in-silico approach. Journal of biomolecular structure \& dynamics, 1-12. Advance online publication. https://doi.org/10.1080/07391102.2020.1778539

[7] Claeson, U. P., Malmfors, T., Wikman, G., \& Bruhn, J. G. (2000). Adhatoda vasica: a critical review of ethnopharmacological and toxicological data. Journal of ethnopharmacology, 72(1-2), 120. https://doi.org/10.1016/s0378-8741(00)00225-7

[8] Corrêa, Geone M., \& Alcântara, Antônio F. de C.. (2012). Chemical constituents and biological activities of species of Justicia: a review. Revista Brasileira de Farmacognosia, 22(1), 220-238. Epub November 01, 2011. https://doi.org/10.1590/S0102-695X2011005000196

[9] Daina, A., Michielin, O. \& Zoete, V. SwissADME: a free web tool to evaluate pharmacokinetics, drug-likeness and medicinal chemistry friendliness of small molecules. Sci Rep 7, 42717 (2017). https://doi.org/10.1038/srep42717

[10] Debiaggi, M., Pagani, L., Cereda, P. M., Landini, P., \& Romero, E. (1988). Antiviral activity of Chamaecyparis lawsoniana extract: study with herpes simplex virus type 2. Microbiologica, 11(1), $55-61$.

[11] Dorsch, W., \& Wagner, H. (1991). New antiasthmatic drugs from traditional medicine?. International archives of allergy and applied immunology, 94(1-4), 262-265. https://doi.org/10.1159/000235378

[12] Eweas, A.F., Maghrabi, I., \& Namarneh, A.I. (2014). Advances in molecular modeling and docking as a tool for modern drug discovery. Sch Res Lib Der Pharma Chem 2014; 6:211e28.

[13] Goel, R.K., Singh, D., Lagunin, A. et al. PASS-assisted exploration of new therapeutic potential of natural products. Med Chem Res 20, 1509-1514 (2011). https://doi.org/10.1007/s00044-010-9398y

[14] Hajjaj, G., Bounihi, A., Tajani, M., Cherrah, Y., Zellou, A., 2013a. Anti-inflammatory evaluation of aqueous extract of Matricaria chamomilla L. (asteraceae) in experimental animal models from Morocco. World J. Pharm. Res. 2 (5), 1218-1228.

[15] Hall, D. C., Jr, \& Ji, H. F. (2020). A search for medications to treat COVID-19 via in silico molecular docking models of the SARS-CoV-2 spike glycoprotein and 3CL protease. Travel medicine and infectious disease, 35, 101646. https://doi.org/10.1016/j.tmaid.2020.101646

[16] Hoffmann, M., Müller, M. A., Drexler, J. F., Glende, J., Erdt, M., Gützkow, T., Losemann, C., Binger, T., Deng, H., Schwegmann-Weßels, C., Esser, K. H., Drosten, C., \& Herrler, G. (2013). Differential sensitivity of bat cells to infection by enveloped RNA viruses: coronaviruses, paramyxoviruses, filoviruses, and influenza viruses. PloS one, 8(8), e72942. https://doi.org/10.1371/journal.pone.0072942

[17] Huang B. (2009). MetaPocket: a meta approach to improve protein ligand binding site prediction. Omics : a journal of integrative biology, 13(4), 325-330. https://doi.org/10.1089/omi.2009.0045 
[18] Islam, R., Parves, M. R., Paul, A. S., Uddin, N., Rahman, M. S., Mamun, A. A., Hossain, M. N., Ali, M. A., \& Halim, M. A. (2020). A molecular modeling approach to identify effective antiviral phytochemicals against the main protease of SARS-CoV-2. Journal of biomolecular structure \& dynamics, 1-12. Advance online publication. https://doi.org/10.1080/07391102.2020.1761883

[19] Khurana, N., Ishar, M. P., Gajbhiye, A., \& Goel, R. K. (2011). PASS assisted prediction and pharmacological evaluation of novel nicotinic analogs for nootropic activity in mice. European journal of pharmacology, 662(1-3), 22-30. https://doi.org/10.1016/j.ejphar.2011.04.048

[20] Kirchdoerfer, R. N., Wang, N., Pallesen, J., Wrapp, D., Turner, H. L., Cottrell, C. A., Corbett, K. S., Graham, B. S., McLellan, J. S., \& Ward, A. B. (2018). Stabilized coronavirus spikes are resistant to conformational changes induced by receptor recognition or proteolysis. Scientific reports, 8(1), 15701. https://doi.org/10.1038/s41598-018-34171-7

[21] Kotwal, G. J., Kaczmarek, J. N., Leivers, S., Ghebremariam, Y. T., Kulkarni, A. P., Bauer, G., De Beer, C., Preiser, W., \& Mohamed, A. R. (2005). Anti-HIV, anti-poxvirus, and anti-SARS activity of a nontoxic, acidic plant extract from the Trifollium species Secomet-V/anti-vac suggests that it contains a novel broad-spectrum antiviral. Annals of the New York Academy of Sciences, 1056(1), 293-302. https://doi.org/10.1196/annals.1352.014

[22] Lei, J., Kusov, Y., \& Hilgenfeld, R. (2018). Nsp3 of coronaviruses: Structures and functions of a large multi-domain protein. Antiviral research, 149, 58-74. https://doi.org/10.1016/j.antiviral.2017.11.001

[23] Li F. (2008). Structural analysis of major species barriers between humans and palm civets for severe acute respiratory syndrome coronavirus infections. Journal of virology, 82(14), 6984-6991. https://doi.org/10.1128/JVI.00442-08

[24] Li, W., Moore, M. J., Vasilieva, N., Sui, J., Wong, S. K., Berne, M. A., Somasundaran, M., Sullivan, J. L., Luzuriaga, K., Greenough, T. C., Choe, H., \& Farzan, M. (2003). Angiotensinconverting enzyme 2 is a functional receptor for the SARS coronavirus. Nature, 426(6965), 450454. https://doi.org/10.1038/nature02145

[25] Lipinski, C. A., Lombardo, F., Dominy, B. W., \& Feeney, P. J. (2001). Experimental and computational approaches to estimate solubility and permeability in drug discovery and development settings. Advanced drug delivery reviews, 46(1-3), 3-26. https://doi.org/10.1016/s0169-409x(00)00129-0

[26] Mukhtar, M., Arshad, M., Ahmad, M., Pomerantz, R. J., Wigdahl, B., \& Parveen, Z. (2008). Antiviral potentials of medicinal plants. Virus research, 131(2), 111-120. https://doi.org/10.1016/j.virusres.2007.09.008

[27] Murugesa mudaliyar KS. Siddha materia media (medicinal plants division). 8th ed. Chennai: Directorate of Indian Medicine \& Homeopathy; 2006. p. 7e713.

[28] Paliwa, J. K., Dwivedi, A. K., Singh, S., \& Gutpa, R. C. (2000). Pharmacokinetics and in-situ absorption studies of a new anti-allergic compound 73/602 in rats. International journal of pharmaceutics, 197(1-2), 213-220. https://doi.org/10.1016/s0378-5173(00)00324-0

[29] Pires, D. E., Blundell, T. L., \& Ascher, D. B. (2015). pkCSM: Predicting Small-Molecule Pharmacokinetic and Toxicity Properties Using Graph-Based Signatures. Journal of medicinal chemistry, 58(9), 4066-4072. https://doi.org/10.1021/acs.jmedchem.5b00104

[30] Pitchiah Kumar, M.; Meenakshi Sundaram, K.; Ramasamy, M.S. Coronavirus Spike (S) Glycoprotein (2019-Ncov) Targeted Siddha Medicines Kabasura Kudineer and Thonthasura Kudineer In silico Evidence for Corona Viral Drug. Asian J. Pharm. Res. Health Care ; 1(12): 2027, 2020. https://doi.org/10.18311/AJPRHC/2020/25103

[31] Pop, R. M., Popolo, A., Trifa, A. P., \& Stanciu, L. A. (2018). Phytochemicals in Cardiovascular and Respiratory Diseases: Evidence in Oxidative Stress and Inflammation. Oxidative medicine and cellular longevity, 2018, 1603872. https://doi.org/10.1155/2018/1603872

[32] Prasanth, D., Murahari, M., Chandramohan, V., Panda, S. P., Atmakuri, L. R., \& Guntupalli, C. (2020). In silico identification of potential inhibitors from Cinnamon against main protease and spike glycoprotein of SARS CoV-2. Journal of biomolecular structure \& dynamics, 1-15. Advance online publication. https://doi.org/10.1080/07391102.2020.1779129 
[33] Salentin, S., Schreiber, S., Haupt, V. J., Adasme, M. F., \& Schroeder, M. (2015). PLIP: fully automated protein-ligand interaction profiler. Nucleic acids research, 43(W1), W443-W447. https://doi.org/10.1093/nar/gkv315

[34] Sarker, A.K., Ahamed, K.U., Chowdhury, J.U., \& Begum, J.M. (2009). Characterization of an Expectorant Herbal Basak Tea Prepared with Adhatoda vasica Leaves. Bangladesh Journal of Scientific and Industrial Research, 44, 211-214. https://doi.org/10.3329/bjsir.v44i2.3674

[35] Shahid M, Dar FK, Ismaeel AY, Al-Mahmeed A, Al Sindi K, Malik A, et al. Plant natural products as a potential source of antimicrobial agents: an overview and a glimpse on recent developments. Recent trends in biotechnology and therapeutic applications of medicinal plants. Dordrecht: Springer; 2013. p. 93e107.

[36] Shaikh, S. A., Jain, T., Sandhu, G., Latha, N., \& Jayaram, B. (2007). From drug target to leads-sketching a physicochemical pathway for lead molecule design in silico. Current pharmaceutical design, 13(34), 3454-3470. https://doi.org/10.2174/138161207782794220

[37] Sinha, S. K., Shakya, A., Prasad, S. K., Singh, S., Gurav, N. S., Prasad, R. S., \& Gurav, S. S. (2020). An in-silico evaluation of different Saikosaponins for their potency against SARS-CoV-2 using NSP15 and fusion spike glycoprotein as targets. Journal of biomolecular structure \& dynamics, 1-12. Advance online publication. https://doi.org/10.1080/07391102.2020.1762741

[38] Sutton, G., Fry, E., Carter, L., Sainsbury, S., Walter, T., Nettleship, J., Berrow, N., Owens, R., Gilbert, R., Davidson, A., Siddell, S., Poon, L. L., Diprose, J., Alderton, D., Walsh, M., Grimes, J. M., \& Stuart, D. I. (2004). The nsp9 replicase protein of SARS-coronavirus, structure and functional insights. Structure (London, England:1993), 12(2),341-353. https://doi.org/10.1016/j.str.2004.01.016

[39] Thokchom P. Singh, Okram M. Singh and Huidrom B. Singh, " Adhatoda vasica Nees: Phytochemical and Pharmacological Profile", The Natural Products Journal (2011) 1: 29. https://doi.org/10.2174/2210315511101010029

[40] Trott, O., \& Olson, A. J. (2010). AutoDock Vina: improving the speed and accuracy of docking with a new scoring function, efficient optimization, and multithreading. Journal of computational chemistry, 31(2), 455-461. https://doi.org/10.1002/jcc.21334

[41] UNNI, SRUTHI; Aouti, Snehal; Balasundaram, Padmanabhan (2020): Identification of a Potent Inhibitor Targeting the Spike Protein of Pandemic Human Coronavirus, SARS-CoV-2 by Computational Methods. ChemRxiv. Preprint. https://doi.org/10.26434/chemrxiv.12197934.v1

[42] Veeresham C. (2012). Natural products derived from plants as a source of drugs. Journal of advanced pharmaceutical technology \& research, 3(4), 200-201. https://doi.org/10.4103/22314040.104709

[43] Wadood, Abdul \& Ahmed, N \& Shah, L \& Ahmad, Ayaz \& Hassan, Hammad \& Shams, Sulaiman. (2013). In-silico drug design: An approach which revolutionarised the drug discovery process. OA Drug Design and Delivery. 1. 10.13172/2054-4057-1-1-1119

[44] Wagner H. (1989). Search for new plant constituents with potential antiphlogistic and antiallergic activity. Planta medica, 55(3), 235-241. https://doi.org/10.1055/s-2006-961992

[45] Wallace, A. C., Laskowski, R. A., \& Thornton, J. M. (1995). LIGPLOT: a program to generate schematic diagrams of protein-ligand interactions. Protein engineering, 8(2), 127-134. https://doi.org/10.1093/protein/8.2.127

[46] Webster, D., Taschereau, P., Lee, T. D., \& Jurgens, T. (2006). Immunostimulant properties of Heracleum maximum Bartr. Journal of ethnopharmacology, 106(3), 360-363. https://doi.org/10.1016/j.jep.2006.01.018

[47] wenzhong, liu; hualan, Li (2020): COVID-19 Disease: ORF8 and Surface Glycoprotein Inhibit Heme Metabolism by Binding to Porphyrin. ChemRxiv. Preprint. https://doi.org/10.26434/chemrxiv.11938173.v3 


\section{aFigures}

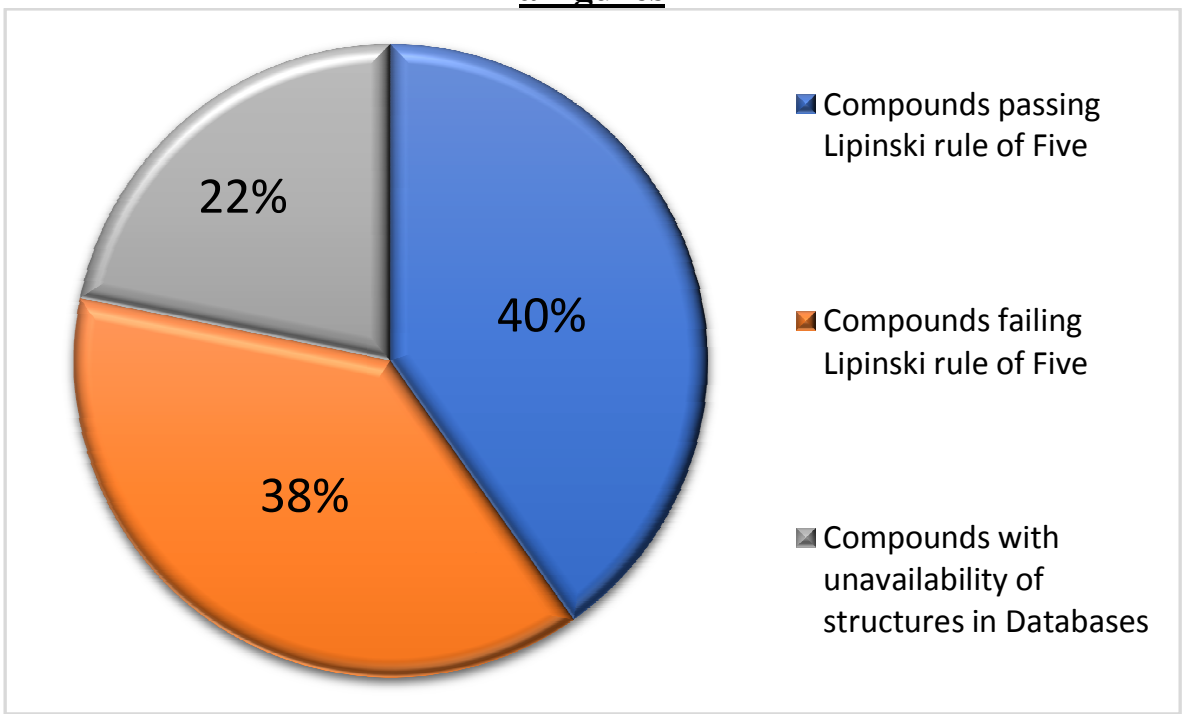

Figure 1: Summary of ADME passed phytocompounds from J. Adhatoda 


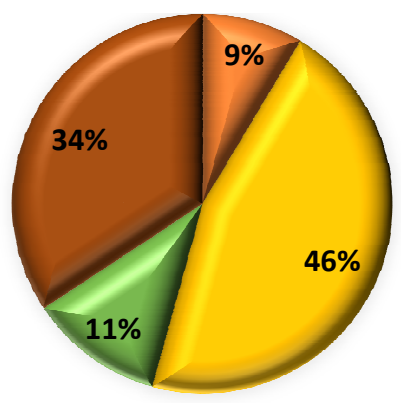

Ligands that failed to satisfy docking score threshold

Ligands that failed AMES test

Ligands that failed hepatotoxicity test

Ligands with good docking score and toxicity profile

Figure 2: Selection of phytocompounds based on docking score $(<-7$ $\mathrm{kcal} / \mathrm{mol}$ ) and toxicity analysis

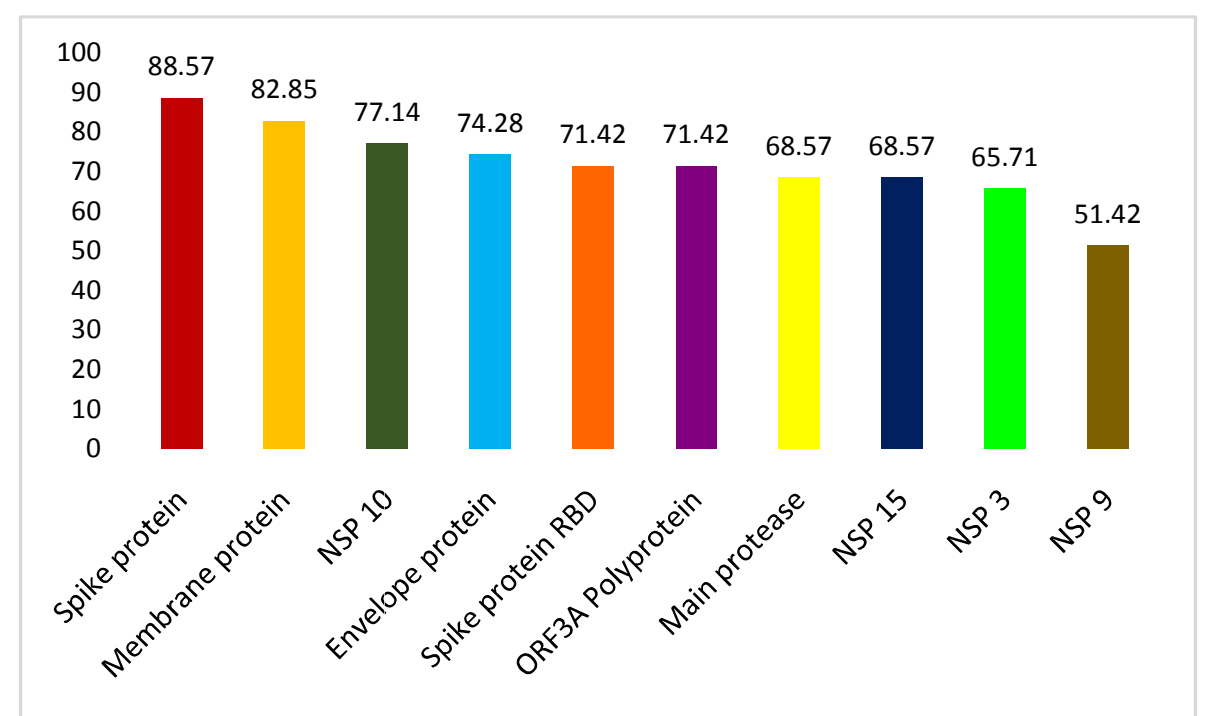

Figure 3: Percentage of phytocompounds showing binding affinity lesser than $-7 \mathrm{kcal} / \mathrm{mol}$ against SARS-CoV-2 proteins 


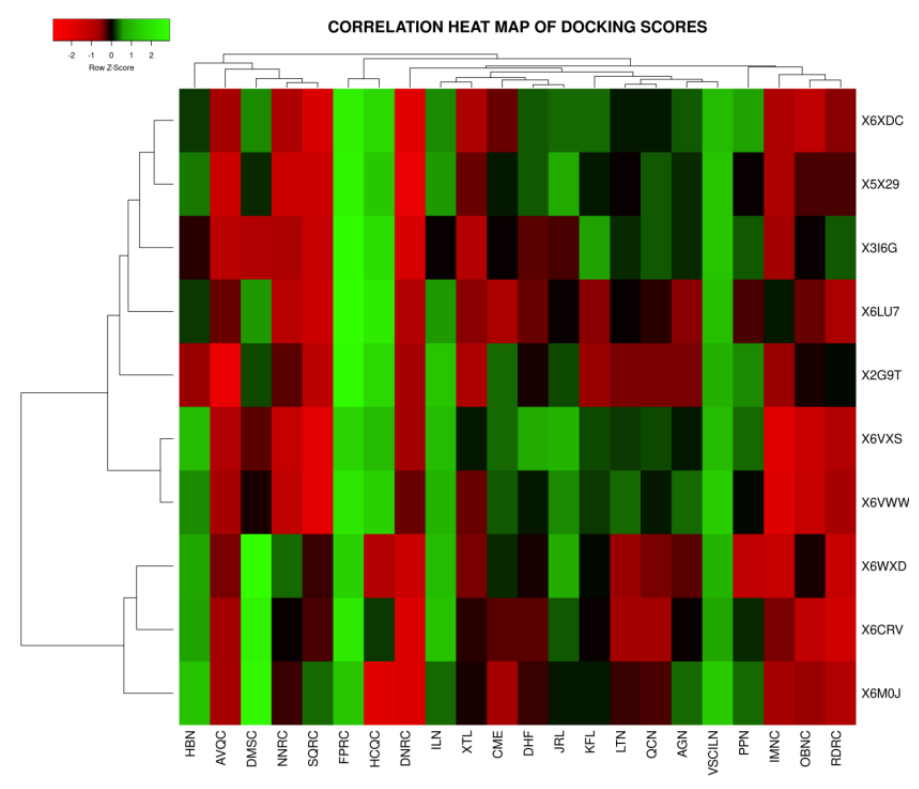

\section{Row Dendrogram}

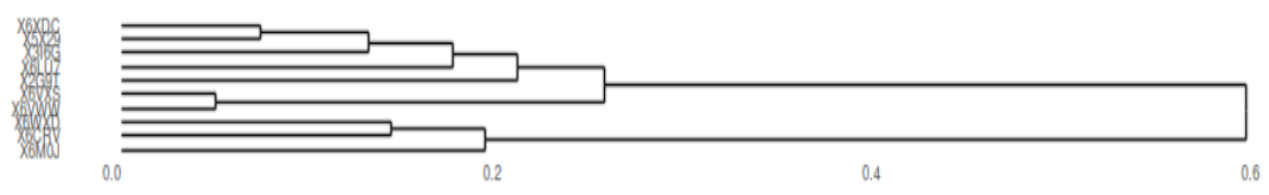

Column Dendrogram

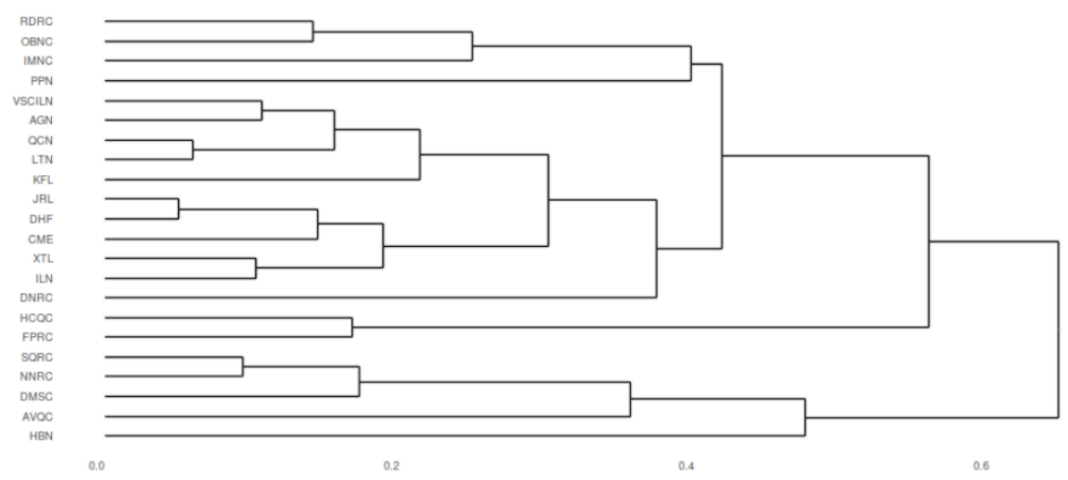

Figure 4: Correlation heat map (Average linkage, Pearson's distance measurement, Scale type: row) generated by Heat mapper online tool for the docking scores of the 12 ligands and 10 FDA approved drugs with the 10 
protein targets of SARS-CoV-2. The left vertical axis represents the SARSCoV-2 targets: X6CRV: Spike Protein, X5X29: Envelope Protein, X3I6G: Membrane Protein, X6LU7: Main Protease, X6M0J: Spike Protein RBD, X6XDC: ORF3a Polyprotein, X6WXD: Nsp3, X2G9T: Nsp9, X6VWW: Nsp10, X6VXS: Nsp15. The horizontal axis represents the 10 FDA approved drugs as positive control followed by 12 ligands: AVQC: Atovaquone, DNRC: Darunavir, DMSC: Dexamethasone, FPRC: Favipiravir, HCQC: Hydroxychloroquine, IMNC: Ivermectin, NNRC: Nelfinavir, OBNC: Ouabain, RDRC: Remedevsir, SQRC: Saquinavir, DHF: 3',4'Dihydroxyflavonol, APG: Apigenin, CME: Chinensinaphthol methyl ether, HBN: Heliobuphthalmin, ILN: Isolariciresinol, JRL: Justiciresinol, KFL: Kaempferol, LTN: Luteolin, PPN: Podophyllotoxin, QCN: quercetin, VSCILN: Vasicilonone, XTL: Xanthoxylol.
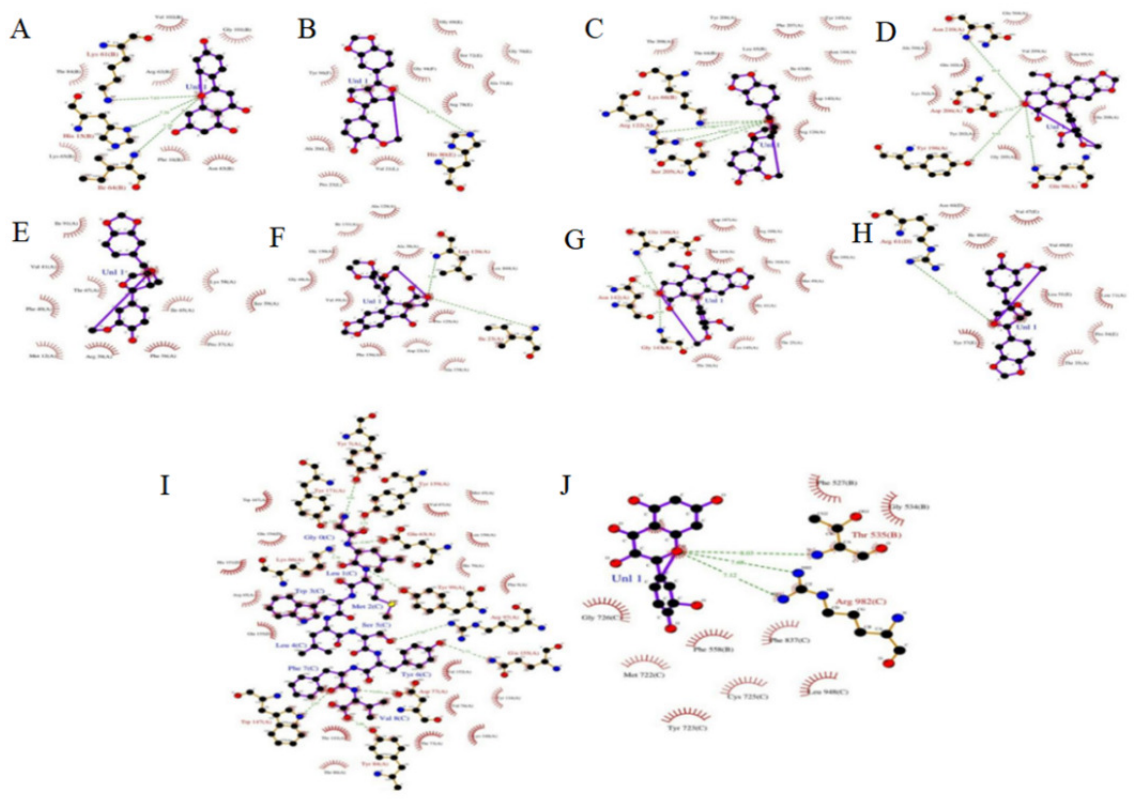

Figure 5: 2D Ligand interaction profile using LIGPLOT: A) Nsp15(6VXS)Apigenin B) Nsp10(6VWW)-Xanthoxylol C) ORF3a Polyprotein(6XDC)Xanthoxylol D) Spike Protein Receptor Binding Domain (6M0J)Chinensinaphthol methyl ether E) Nsp9(2G9T)-Xanthoxylol F) Nsp3(6WXD)Podophyllotoxin G) Main Protease(6LU7)-Chinensinaphthol methyl ether H) Envelope Protein(5X29)-Xanthoxylol I) Membrane Protein(3I6G)Xanthoxylol J) Spike Protein(6CRV)-Quercetin 
Tables

Table 1: Phytocompounds from J. adhatoda and FDA approved repurposed drugs

$\begin{array}{lll}\text { S Compo } & \\ \text { N und } & \text { Source/ID } \\ & \\ & \\ \text { 10H- } & \\ \text { quindo } & \text { PubChem } \\ \text { line } & 98912\end{array}$

2acetylb PubChem enzyla 22379528 mine
$3-$ hydrox PubChem yanisot 101670821 ine
Structure
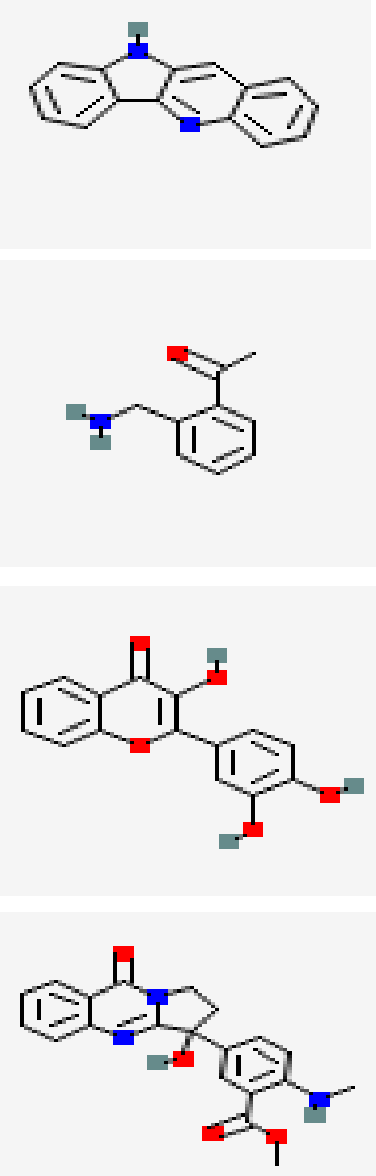

Pharmacologic
al function

Anticancer https://pubmed.nc activity and bi.nlm.nih.gov/22 cellular 691117/

repression of cMYC

https://doi.org/10. 1016/j.biopha.201

Anticancer

7.06.096
Jimenez et al.. 2001; Wang et al.. Antioxidant, 2004; Woodman prevents et al.. 2005; diabetes and Woodman \& vasodilator Malakul, 2009

DOI:

10.3329/dujs.v60i Antibacterial 1.10326

Neoandrographoli de Isolated from leaves of Adhatoda vasica 
9-

acetam

ido- 3,4 dihydr opyrid o- $(3,4-$

b)

Adhato PubChem dine $\quad 52908915$

Anisoti PubChem ne 442884

Apigen PubChem in $\quad 5280443$

Chinen sinapht hol methyl PubChem 5315828

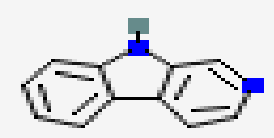

Neurotherapeut ic for cocaine related disorders
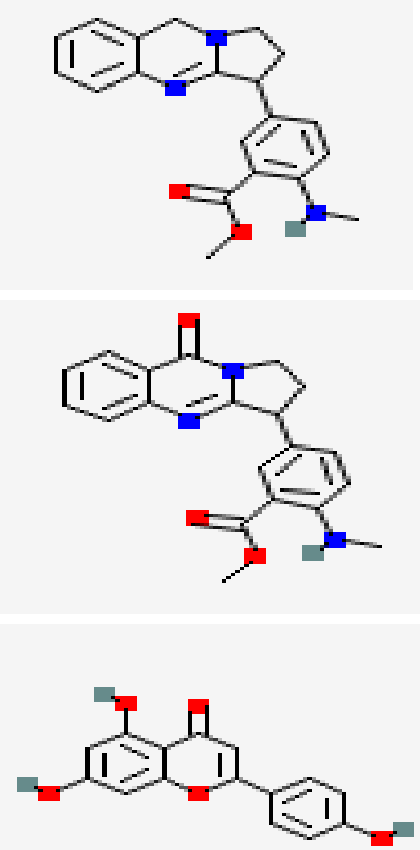

Antiinflammatory and anti-tumor

Day et al.. 1999

https://pubmed.nc

bi.nlm.nih.gov/11

418284/

https://pubmed.nc bi.nlm.nih.gov/26 142781/

Appl Biochem

Biotechnol

anti- 2012

tuberculosis Nov;168(5):980activity

90. doi:

10.1007/s12010-

012-9834-1. Epub

Wahi et al.. 1974:

Sawatzky et al.. 2006: Cai et

al., 2011

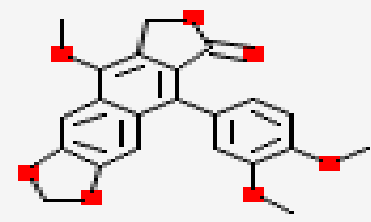

Antiplatelet

aggregation 


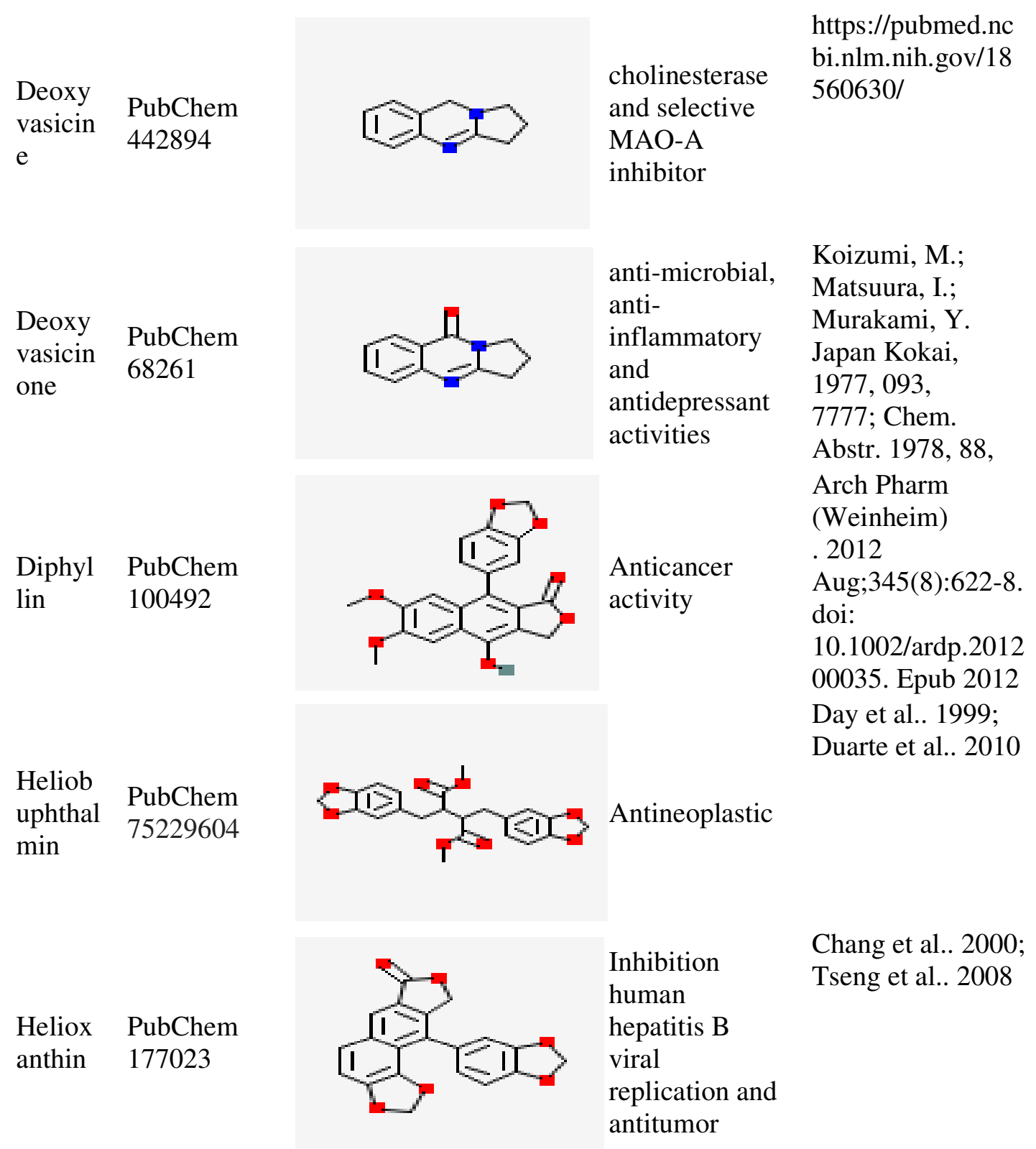


Isolaric iresinol

PubChem 160521

$\begin{array}{ll}\text { Justici } & \text { PubChem } \\ \text { din B } & 442882\end{array}$

Justici PubChem $\operatorname{din} \mathrm{D} \quad 5318737$

Justici PubChem din $\mathrm{E} \quad 363128$

Justici

PubChem $\operatorname{din} \mathrm{A}$

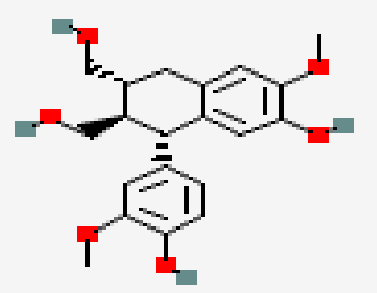

Kupeli et al., 2003

Anti-

inflammatory

Anti-

Baba et at. 1996;

inflammatory, antiplatelet

Catch et al., 2003;

Kavitha et al., aggregation, 2003; Rao et al.. cytotoxicity, 2006; Wu et al.. antiviral, 2007; Kaur et at, fungicidal. 2009

Fukamiya \& Lee. 1986; Chen et al., 1996; Wu et al. aggregation 2007

Fukamiya \& Lee, 1986; Asano et al.. 1996

https://doi.org/10. inhibitor of $\quad \underline{1016 / S 0960-}$ leukotriene $\quad \underline{894 X(01) 81016-7}$ biosynthesis by human leukocytes

Anti-cancer $\quad$ https://doi.org/10. activity, 1007/s11064-016Cytotoxic $\underline{1857-5}$ activities https://doi.org/10. against 1007/s00044-009hepatocellular $\quad$ 9172-1 carcinoma, 


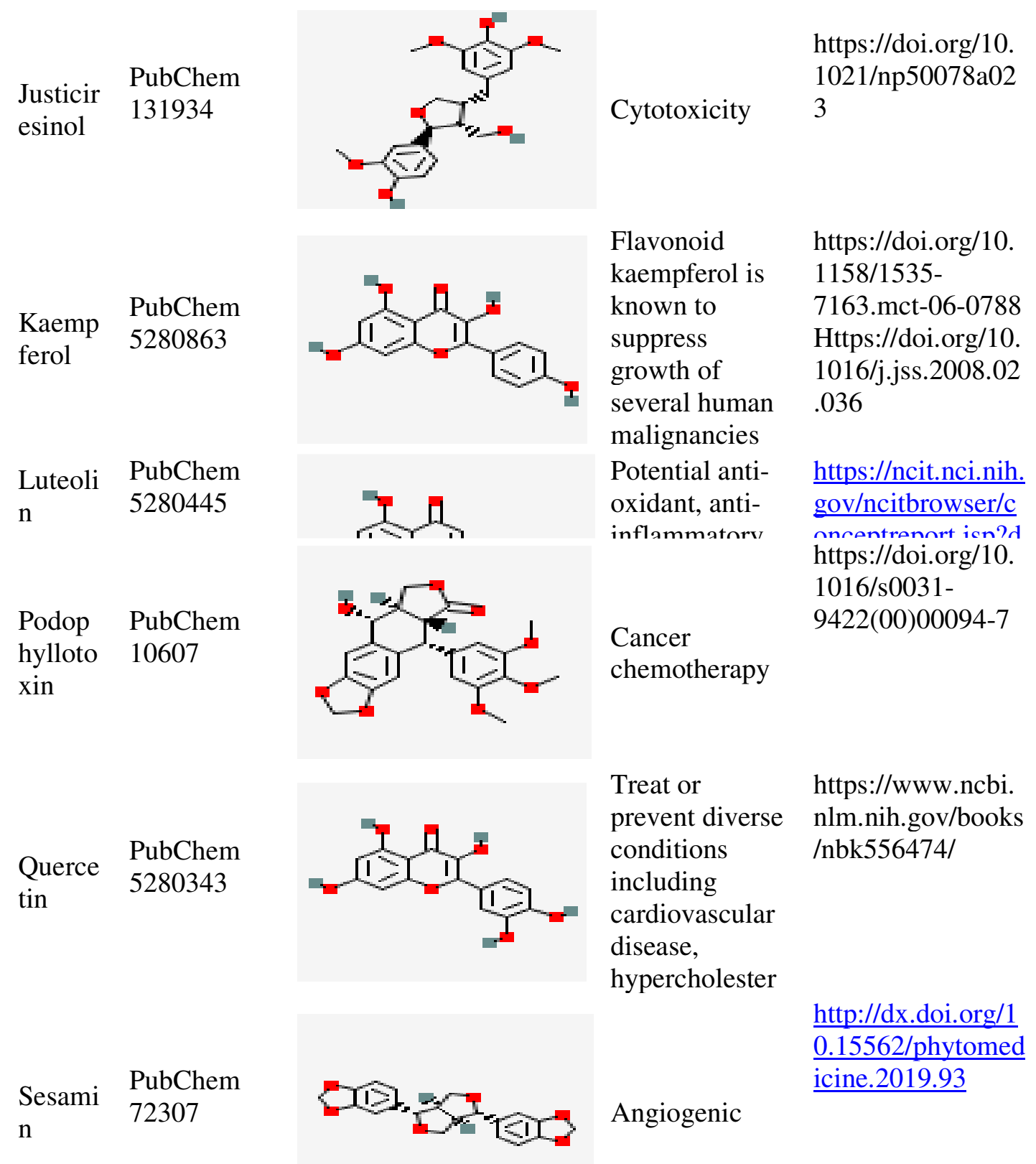


$\begin{array}{ll}\text { Taiwan } & \text { PubChem49 } \\ \text { in E } & 3164\end{array}$

in $\mathrm{E}$

Taiwan

in $\mathrm{E}$

methyl

ether

Umbell

iferone

PubChem

11740369

PubChem 5281426
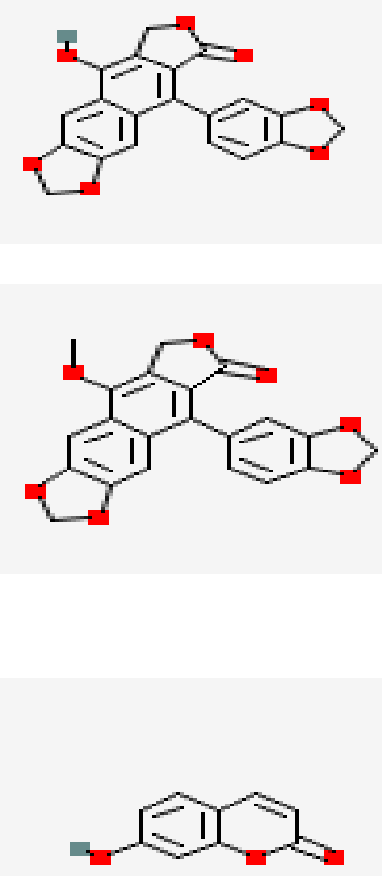

PubChem

Vasici

nolone

158720

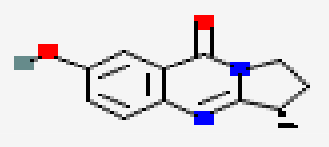

$\begin{array}{ll}\text { Vasici } & \text { PubChem } \\ \text { ne } & 72610\end{array}$ https://doi.org/10.

1021/np960443+

Antiplatelet https://doi.org/10.

aggregation 1016/s0031-

and antitumor 9422(00)00275-2

Antiplatelet http://dx.doi.org/1

aggregation $\quad \underline{0.15562 / \text { phytomed }}$

and

cytotoxicity

against human

cervical

carcinoma

Anti-

icine. 2019.93

https://doi.org/10.

1021/np9900167

https://doi.org/10.

1021/np960443+

inflammatory,

https://doi.org/10.

1590/s0102-

antinociceptive

, and

$\underline{695 \times 20110050001}$

96

bronchodilator

activities.

Treatment of

respiratory

diseases

anti-

inflammatory

and

antimicrobial

.. .

Treatment of

bronchitis https://pubmed.nc bi.nlm.nih.gov/23 357363/

https://doi.org/10. 1021/jo01037a041

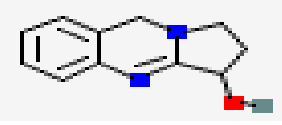




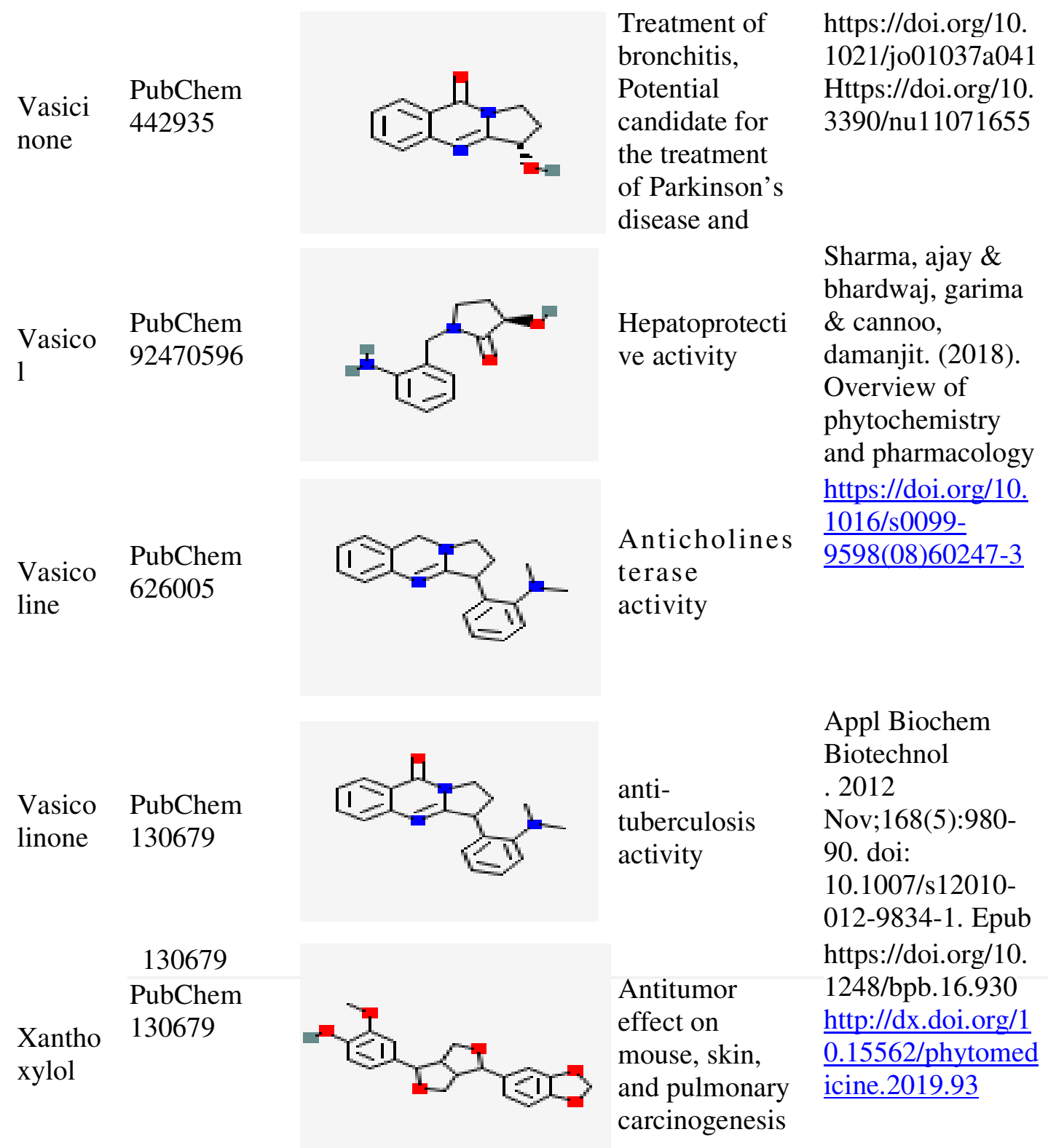

FDA Approved Repurposed COVID 19 Drugs 


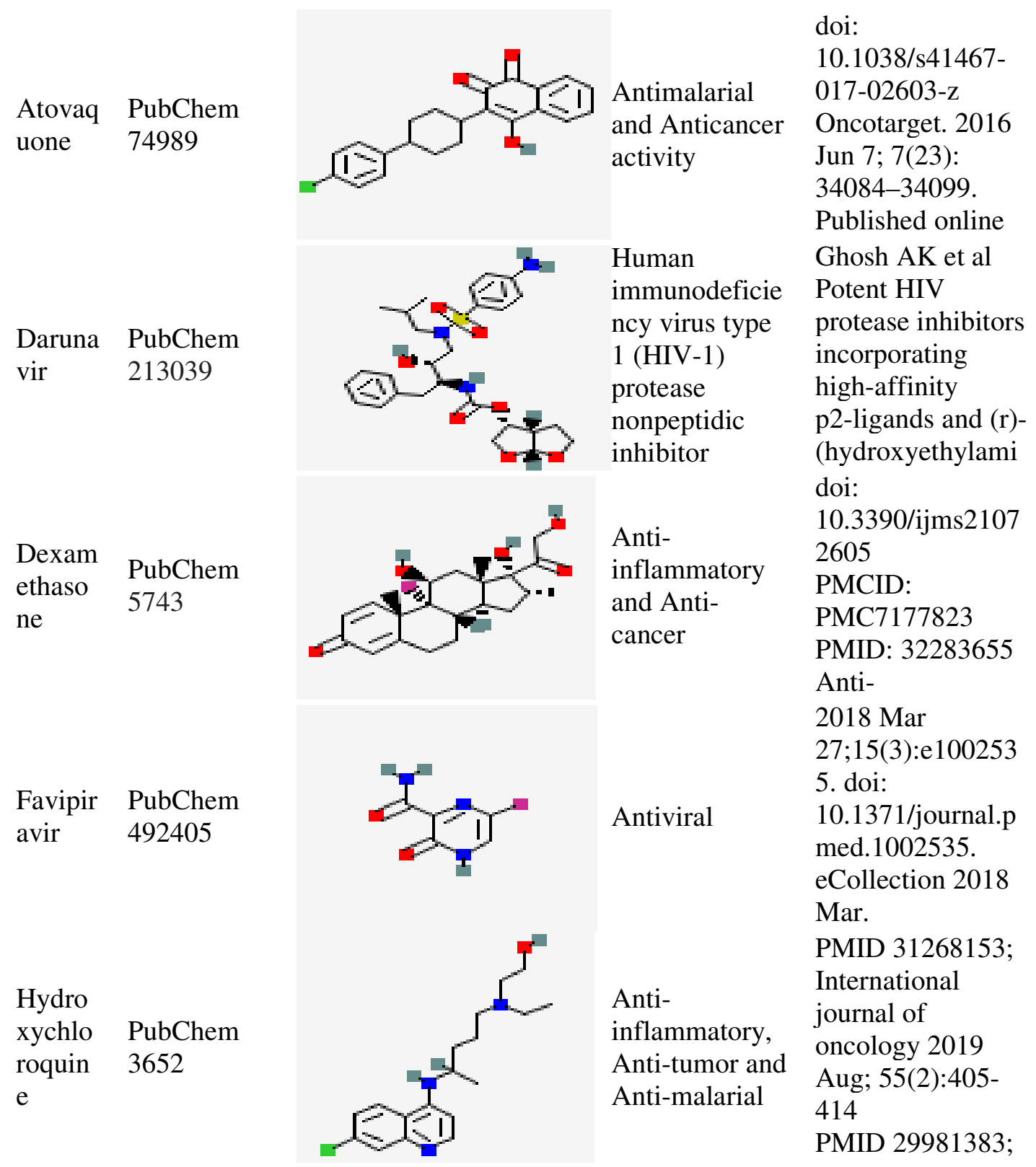




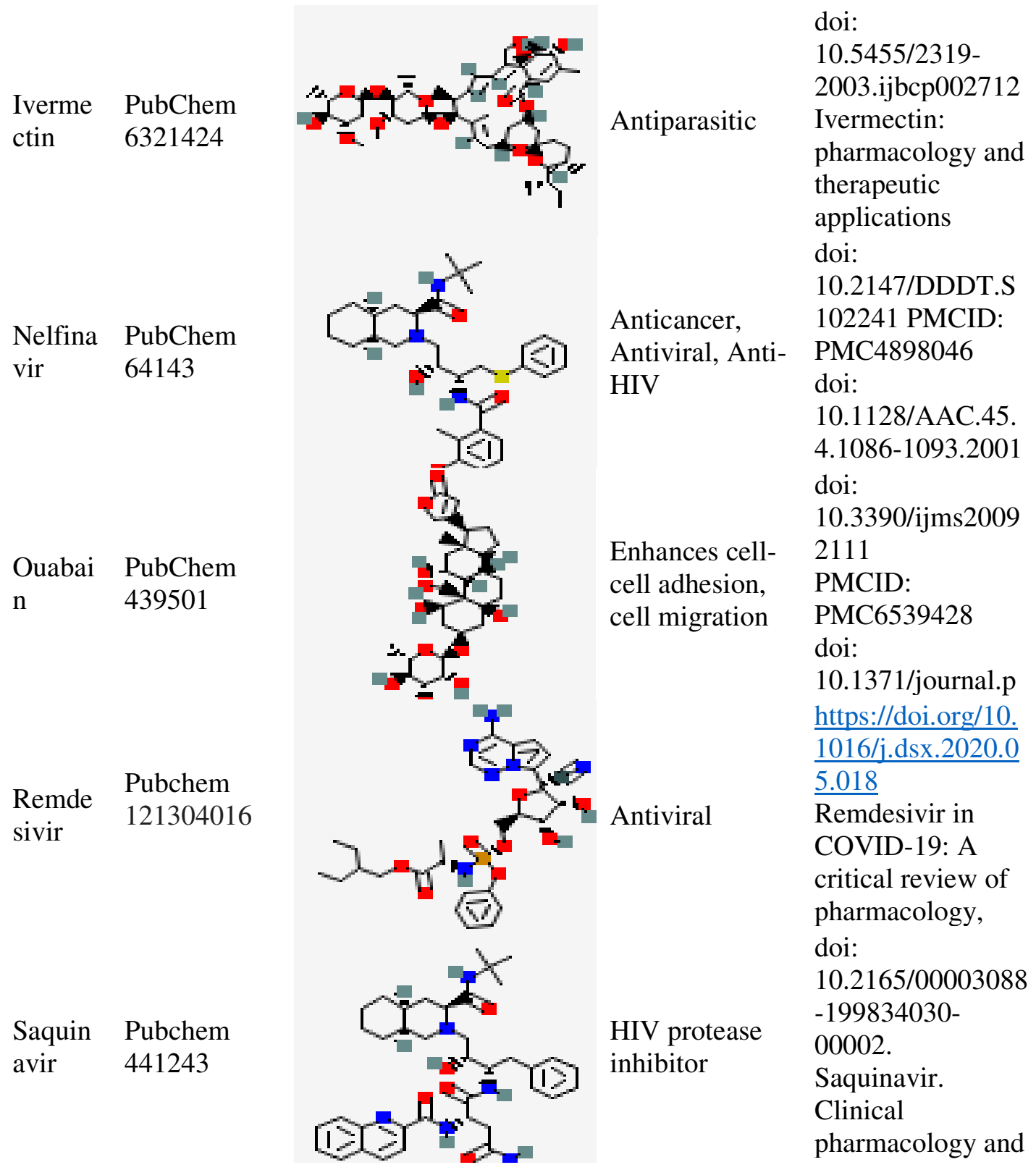

Table 2: Grid parameters ofSARS - CoV2 target proteins

$\begin{array}{cccccc}\text { S.No } & \text { Protein } & \text { PDB } & \text { xyz coordinates of grid } & \text { xyz } & \text { Spacing } \\ & & \text { ID } & \text { center }(\square) & \text { coordinates } & (\square)\end{array}$




\begin{tabular}{|c|c|c|c|c|c|}
\hline & & & & $\begin{array}{c}\text { of grid size } \\
(\square)\end{array}$ & \\
\hline 1 & $\begin{array}{l}\text { Spike } \\
\text { protein }\end{array}$ & 6CRV & $162.996,164.796,153.525$ & $82,82,90$ & 1.000 \\
\hline 2 & $\begin{array}{l}\text { Envelope } \\
\text { protein }\end{array}$ & $5 \times 29$ & $5.513,-0.464,6.602$ & $40,40,40$ & 0.503 \\
\hline 3 & $\begin{array}{l}\text { Membrane } \\
\text { protein }\end{array}$ & $3 \mathrm{I} 6 \mathrm{G}$ & $26.338,1.956,45.596$ & $40,40,40$ & 0.503 \\
\hline 4 & Protease & 6LU7 & $-11.028,14.333,68.191$ & $40,40,40$ & 0.500 \\
\hline 5 & $\begin{array}{l}\text { Spike } \\
\text { protein } \\
\text { receptor } \\
\text { binding } \\
\text { domain }\end{array}$ & $6 \mathrm{M} 0 \mathrm{~J}$ & $-26.827,18.465,-9.269$ & $30,50,88$ & 1.000 \\
\hline 6 & ORF 3a & $6 \mathrm{XDC}$ & $145.801,145.378,153.392$ & $40,40,40$ & 0.500 \\
\hline 7 & $\begin{array}{l}\text { Non } \\
\text { structural } \\
\text { protein } 3 \\
\text { (Nsp3) }\end{array}$ & $6 \mathrm{WXD}$ & $5.513,0.464,6.602$ & $40,40,40$ & 0.503 \\
\hline 8 & $\begin{array}{l}\text { Non } \\
\text { structural } \\
\text { protein } 9 \\
\text { (Nsp9) }\end{array}$ & 2G9T & $56.325,1.573,21.494$ & $40,40,40$ & 0.500 \\
\hline 9 & $\begin{array}{l}\text { Non } \\
\text { structural } \\
\text { protein } 10 \\
(\text { Nsp10) }\end{array}$ & $6 \mathrm{VWW}$ & $119.130,121.902,81.992$ & $76,82,126$ & 1.000 \\
\hline 10 & $\begin{array}{l}\text { Non } \\
\text { strucral } \\
\text { protein } 15 \\
\text { (Nsp15) }\end{array}$ & $6 \mathrm{VXS}$ & $-69.046,26.670,-0.197$ & $56,58,52$ & 0.878 \\
\hline
\end{tabular}

Table 3: Lipinski rule of five parameters for the selected phytocompounds

\begin{tabular}{|c|c|c|c|c|c|c|c|c|c|}
\hline & & & & & & & & & \\
\hline j.No. & Compound & $\begin{array}{c}\text { Form } \\
\text { ula }\end{array}$ & MW & ilogP & $\mathrm{X} \log \mathrm{P} 3$ & WlogP & $\mathrm{M} \log \mathrm{P}$ & $\begin{array}{l}\text { Sillico } \\
\text { s- } \\
\text { ITlogP }\end{array}$ & $\begin{array}{l}\text { Consens } \\
\text { us } \log \mathrm{P}\end{array}$ \\
\hline
\end{tabular}




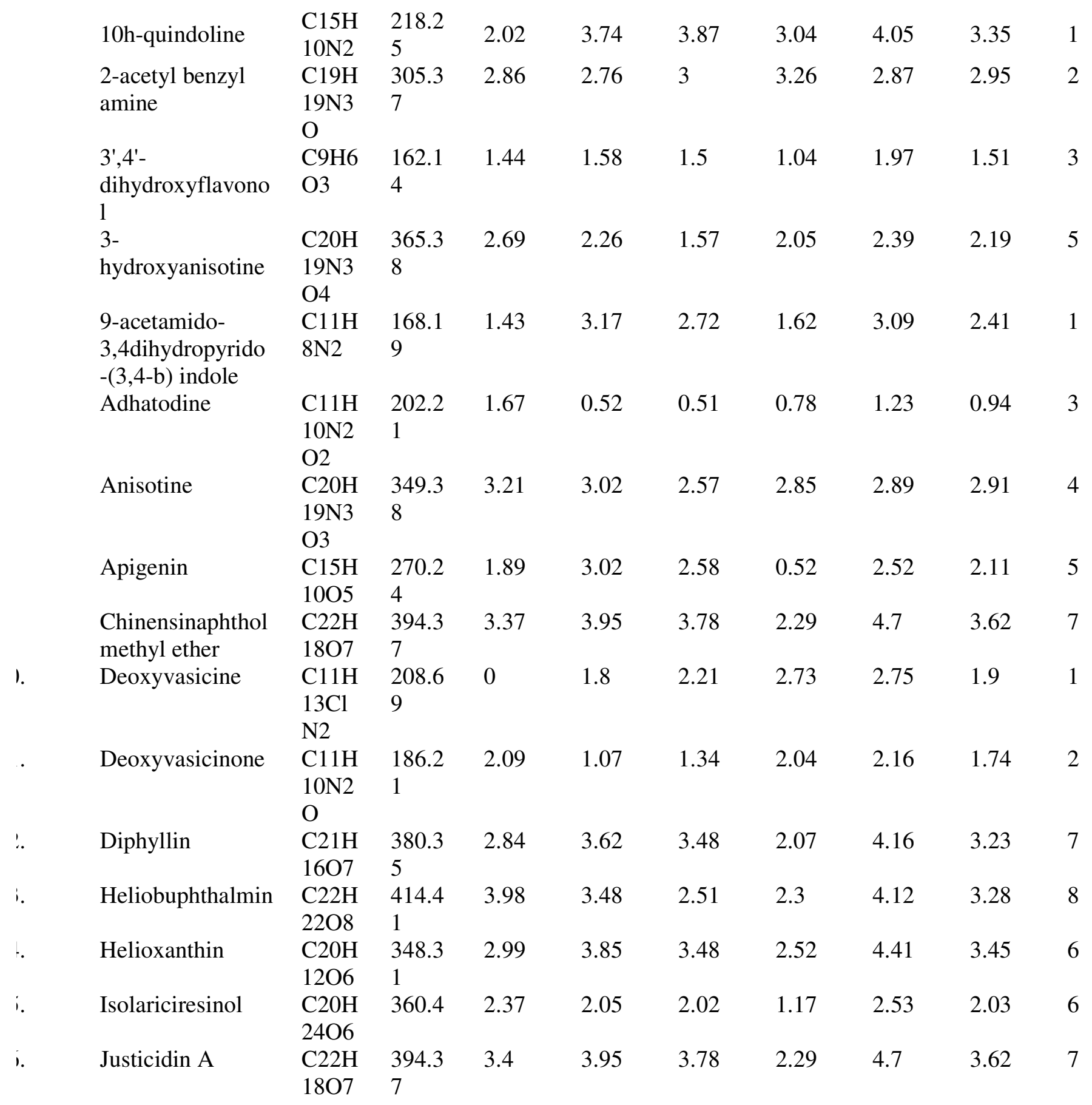




\begin{tabular}{|c|c|c|c|c|c|c|c|c|c|}
\hline '. & Justicidin B & $\begin{array}{l}\mathrm{C} 21 \mathrm{H} \\
16 \mathrm{O}\end{array}$ & $\begin{array}{l}364.3 \\
5\end{array}$ & 3.15 & 3.98 & 3.77 & 2.34 & 4.64 & 3.58 \\
\hline i. & Justicidin D & $\begin{array}{l}\mathrm{C} 21 \mathrm{H} \\
14 \mathrm{O} 7\end{array}$ & $\begin{array}{l}378.3 \\
3\end{array}$ & 3.22 & 3.82 & 3.49 & 2.48 & 4.44 & 3.49 \\
\hline '. & Justicidin E & $\begin{array}{l}\mathrm{C} 20 \mathrm{H} \\
12 \mathrm{O} 6\end{array}$ & $\begin{array}{l}348.3 \\
1\end{array}$ & 3.1 & 3.85 & 3.48 & 2.52 & 4.41 & 3.47 \\
\hline I. & Justiciresinol & $\begin{array}{l}\mathrm{C} 21 \mathrm{H} \\
26 \mathrm{O} 7\end{array}$ & $\begin{array}{l}390.4 \\
3\end{array}$ & 3.04 & 2.37 & 2.34 & 0.86 & 2.93 & 2.31 \\
\hline . & Kaempferol & $\begin{array}{l}\mathrm{C} 15 \mathrm{H} \\
10 \mathrm{O} 6\end{array}$ & $\begin{array}{l}286.2 \\
4\end{array}$ & 1.7 & 1.9 & 2.28 & -0.03 & 2.03 & 1.58 \\
\hline$\therefore$ & Luteolin & $\begin{array}{l}\mathrm{C} 15 \mathrm{H} \\
10 \mathrm{O} 6\end{array}$ & $\begin{array}{l}286.2 \\
4\end{array}$ & 1.86 & 2.53 & 2.28 & -0.03 & 2.03 & 1.73 \\
\hline i. & Podophyllotoxin & $\begin{array}{l}\mathrm{C} 22 \mathrm{H} \\
22 \mathrm{O} 8\end{array}$ & $\begin{array}{l}414.4 \\
1\end{array}$ & 3.25 & 2.01 & 2.08 & 1.43 & 2.9 & 2.33 \\
\hline$\cdot$ & Quercetin & $\begin{array}{l}\mathrm{C} 15 \mathrm{H} \\
10 \mathrm{O} 6\end{array}$ & $\begin{array}{l}286.2 \\
4\end{array}$ & 1.7 & 1.9 & 2.28 & -0.03 & 2.03 & 1.58 \\
\hline i. & Sesamin & $\begin{array}{l}\mathrm{C} 20 \mathrm{H} \\
18 \mathrm{O} 6\end{array}$ & $\begin{array}{l}354.3 \\
5\end{array}$ & 3.46 & 2.68 & 2.57 & 1.98 & 3.25 & 2.79 \\
\hline i. & Taiwanin E & $\begin{array}{l}\mathrm{C} 20 \mathrm{H} \\
12 \mathrm{O} 7\end{array}$ & $\begin{array}{l}364.3 \\
1\end{array}$ & 2.79 & 3.49 & 3.19 & 2.26 & 3.92 & 3.13 \\
\hline '. & $\begin{array}{l}\text { Taiwanin E } \\
\text { methyl ether }\end{array}$ & $\begin{array}{l}\mathrm{C} 21 \mathrm{H} \\
14 \mathrm{O} 7\end{array}$ & $\begin{array}{l}378.3 \\
3\end{array}$ & 3.27 & 3.82 & 3.49 & 2.48 & 4.44 & 3.5 \\
\hline i. & Umbelliferone & $\begin{array}{l}\text { C9H6 } \\
\text { O3 }\end{array}$ & $\begin{array}{l}162.1 \\
4\end{array}$ & 1.44 & 1.58 & 1.5 & 1.04 & 1.97 & 1.51 \\
\hline '. & Vasicine & $\begin{array}{l}\mathrm{C} 11 \mathrm{H} \\
12 \mathrm{~N} 2 \\
\mathrm{O}\end{array}$ & $\begin{array}{l}188.2 \\
3\end{array}$ & 1.94 & 0.44 & 0.38 & 1.57 & 1.8 & 1.23 \\
\hline I. & Vasicinolone & $\begin{array}{l}\mathrm{C} 11 \mathrm{H} \\
10 \mathrm{~N} 2 \\
\mathrm{O} 3\end{array}$ & $\begin{array}{l}218.2 \\
1\end{array}$ & 1.53 & 0.03 & 0.21 & 0.63 & 0.72 & 0.62 \\
\hline . & Vasicinone & $\begin{array}{l}\mathrm{C} 11 \mathrm{H} \\
10 \mathrm{~N} 2 \\
\mathrm{O} 2\end{array}$ & $\begin{array}{l}202.2 \\
1\end{array}$ & 1.67 & 0.52 & 0.51 & 0.78 & 1.23 & 0.94 \\
\hline$\therefore$ & Vasicol & $\begin{array}{l}\mathrm{C} 11 \mathrm{H} \\
14 \mathrm{~N} 2 \\
\mathrm{O} 2\end{array}$ & $\begin{array}{l}206.2 \\
4\end{array}$ & 1.44 & 0.05 & -0.16 & 0.32 & 0.68 & 0.46 \\
\hline i. & Vasicoline & $\begin{array}{l}\text { C19H } \\
21 \mathrm{~N} 3\end{array}$ & $\begin{array}{l}291.3 \\
9\end{array}$ & 2.79 & 2.81 & 2.87 & 3.63 & 3.42 & 3.11 \\
\hline$\therefore$ & Vasicolinone & $\begin{array}{l}\text { C19H } \\
19 \mathrm{~N} 3\end{array}$ & $\begin{array}{l}305.3 \\
7\end{array}$ & 2.86 & 2.76 & 3 & 3.26 & 2.87 & 2.95 \\
\hline
\end{tabular}




$$
\begin{aligned}
& \text { i. } \begin{array}{llllllllll}
\mathrm{C} 20 \mathrm{H} & 356.3 & 3.25 & 2.48 & 2.56 & 1.57 & 2.96 & 2.56 & 6
\end{array} \\
& \text { MW - Molecular Weight MR - Molar Refractivity }
\end{aligned}
$$

Table 4: Toxicity profile for the lead molecules

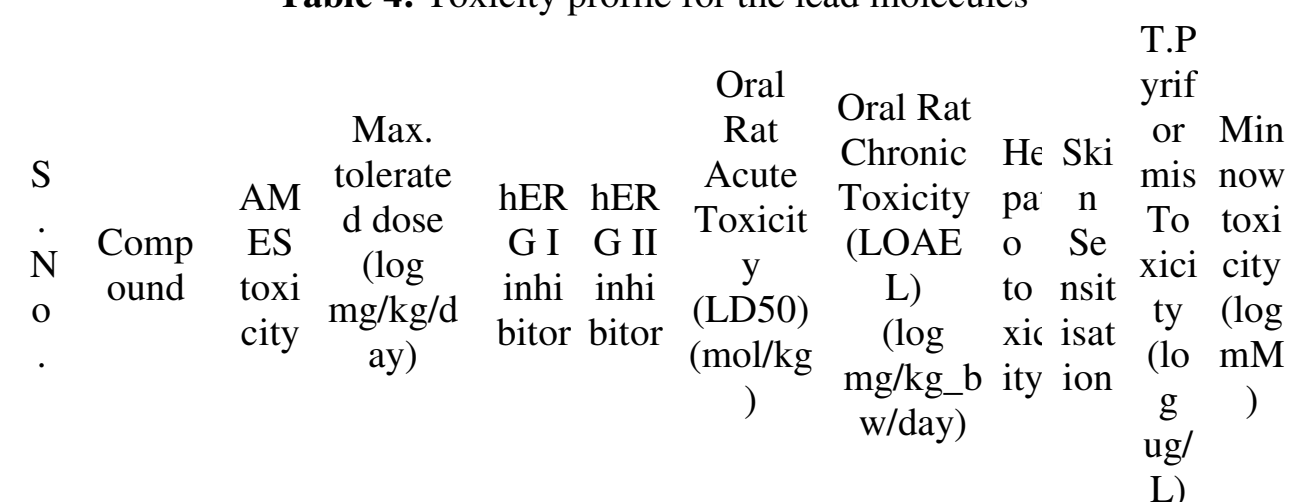

1. $3^{\prime}, 4^{\prime}-$

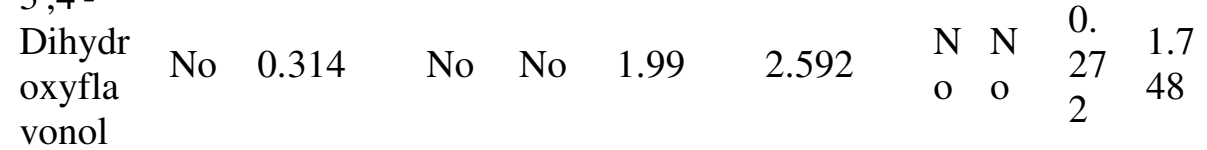

$$
\begin{aligned}
& \begin{array}{lllllllllll}
\text { 2. } & \text { Apige } \\
\text { nin } & \text { No } & 0.337 & \text { No } & \text { No } & 1.978 & 1.959 & \text { N } & \text { N } & 0 . & 1.1 \\
& & & & & &
\end{array}
\end{aligned}
$$

3. Chinen sinapht hol Methyl No $\quad 0.307$ No Yes 3.053 Ether

4. Heliob

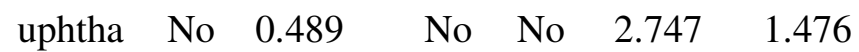
lmin

5. Isolari $\begin{array}{llllll}\text { ciresin } & \text { No } & -0.019 & \text { No } & \text { Yes } & 2.003\end{array}$

\begin{tabular}{|c|c|c|c|c|c|c|c|c|c|}
\hline $\begin{array}{l}\text { Justicir } \\
\text { esinol }\end{array}$ & No & 0.276 & No & No & 2.109 & 1.519 & $\begin{array}{l}\mathrm{N} \\
\mathrm{O}\end{array}$ & $\mathrm{N}$ & $\begin{array}{l}0 \\
45 \\
3\end{array}$ \\
\hline
\end{tabular}
ol

6. 


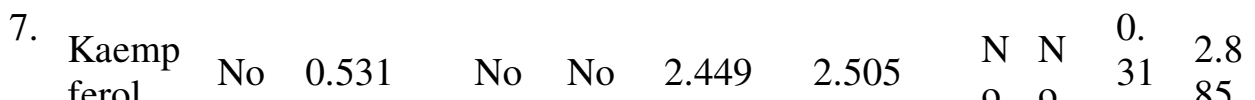

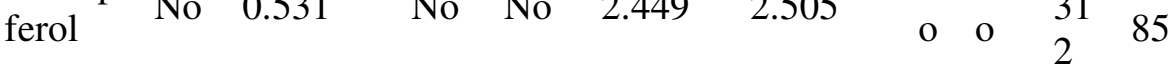

$\begin{array}{lllllllllll}\text { 8. Luteoli No } & 0.564 & \text { No } & \text { No } & 2.453 & 1.537 & \mathrm{~N} & \mathrm{~N} & \begin{array}{l}0 . \\ 42\end{array} & 1.3\end{array}$ $\begin{array}{lllllll}\mathrm{n} & \mathrm{N} & \mathrm{O} & \mathrm{o} & 42 & 46\end{array}$

9. Podop $\quad \mathrm{N} \quad \mathrm{N} \quad 0$.

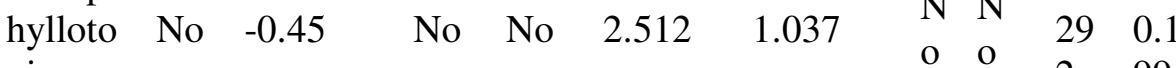
$\begin{array}{llllll}\text { xin } & 0 & 0 & 2 & 99\end{array}$ $\begin{array}{lllllllllll}10 & \\ \begin{array}{l}\text { Querce } \\ \text { tin }\end{array} & \text { No } & 0.499 & \text { No } & \text { No } & 2.471 & 2.612 & \text { N } & \text { N } & 0 . & 1.3 \\ & & & & & & 0 & 28 & 01\end{array}$

11 Vasicil $\quad 0.246 \quad$ No $\quad \begin{array}{llllll}1.331 & \mathrm{~N} & \mathrm{~N} & 0 . & 1.7\end{array}$ $\begin{array}{llllllllll}\text { onone No } & 0.246 & \text { No } & \text { No } & 1.813 & 1.331 & \text { o } & 0 & 55 & 23\end{array}$

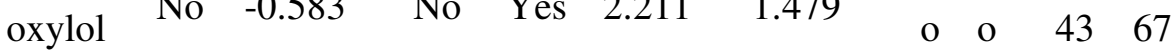

Table 5: Docking scores of phytocompounds against SARS-CoV-2 target

\begin{tabular}{|c|c|c|c|c|c|c|c|c|c|c|c|}
\hline \multirow{3}{*}{$\begin{array}{l}\text { S. } \\
\text { N } \\
\text { o. }\end{array}$} & \multirow[b]{2}{*}{$\begin{array}{c}\text { Molecule/targe } \\
\text { t protein }\end{array}$} & \multicolumn{10}{|c|}{ Binding energy (kcal/mol) } \\
\hline & & $\begin{array}{c}\text { Spi } \\
\text { ke } \\
\text { pro } \\
\text { tei } \\
\text { n }\end{array}$ & $\begin{array}{c}\text { Env } \\
\text { elop } \\
\mathrm{e} \\
\text { prot } \\
\text { ein }\end{array}$ & $\begin{array}{c}\text { Mem } \\
\text { bran } \\
\mathrm{e} \\
\text { prote } \\
\text { in }\end{array}$ & $\begin{array}{c}\text { Prot } \\
\text { eas } \\
\text { e }\end{array}$ & $\begin{array}{c}\text { Spi } \\
\text { ke } \\
\text { prot } \\
\text { ein } \\
\text { rec } \\
\text { ept } \\
\text { or } \\
\text { bin } \\
\text { din } \\
\text { g } \\
\text { do } \\
\text { mia } \\
\text { n }\end{array}$ & $\begin{array}{l}\mathrm{O} \\
\mathrm{R} \\
\mathrm{F} \\
3 \mathrm{a}\end{array}$ & $\begin{array}{c}\mathrm{N} \\
\mathrm{SP} \\
3\end{array}$ & $\begin{array}{l}\mathrm{N} \\
\mathrm{S} \\
\mathrm{P} \\
9\end{array}$ & $\begin{array}{l}\mathrm{N} \\
\mathrm{S} \\
\mathrm{P} \\
1 \\
0\end{array}$ & $\begin{array}{c}\text { NS } \\
\text { P1 } \\
5\end{array}$ \\
\hline & $\begin{array}{l}\text { 3',4'- } \\
\text { Dihydroxyflav } \\
\text { onol }\end{array}$ & $\overline{8} 8.8$ & -7.5 & -8.9 & -7.7 & -8.3 & $\begin{array}{l}- \\
7 . \\
5\end{array}$ & $\begin{array}{l}- \\
7 . \\
3\end{array}$ & -7 & $\begin{array}{l}- \\
8 . \\
3\end{array}$ & $\begin{array}{l}- \\
7.3\end{array}$ \\
\hline
\end{tabular}




\begin{tabular}{|c|c|c|c|c|c|c|c|c|c|c|}
\hline Apigenin & $-\overline{8}$ & -7.7 & -8.4 & -7.8 & -7.7 & $\begin{array}{l}- \\
7 . \\
5\end{array}$ & $\begin{array}{l}- \\
7 . \\
5\end{array}$ & $\begin{array}{l}- \\
7 . \\
3\end{array}$ & -8 & -8 \\
\hline $\begin{array}{l}\text { Chinensinapht } \\
\text { hol methyl } \\
\text { ether }\end{array}$ & 8.8 & -7.8 & -8.6 & -8 & -8.8 & $\begin{array}{l}- \\
8 . \\
2\end{array}$ & $\begin{array}{l}- \\
7 . \\
1\end{array}$ & $\begin{array}{l}- \\
6 . \\
6\end{array}$ & $\begin{array}{l}- \\
8 . \\
1\end{array}$ & $\overline{7}-7.7$ \\
\hline $\begin{array}{l}\text { Heliobuphthal } \\
\text { min }\end{array}$ & $\overline{7}-8$ & -7.3 & -8.7 & -7.2 & -6.9 & $\begin{array}{l}- \\
7 . \\
6\end{array}$ & $\begin{array}{l}- \\
6 . \\
7\end{array}$ & $\begin{array}{l}- \\
7 . \\
4\end{array}$ & $\begin{array}{l}- \\
7 . \\
9\end{array}$ & $-\overline{6}$ \\
\hline Isolariciresinol & $\overline{7}-\overline{2}$ & -7.2 & -8.6 & -6.9 & -7.7 & $\begin{array}{l}- \\
7 . \\
3\end{array}$ & $\begin{array}{l}- \\
6 . \\
4\end{array}$ & $\begin{array}{l}- \\
5 . \\
9\end{array}$ & $\begin{array}{l}- \\
7 . \\
5\end{array}$ & $-\overline{6}$ \\
\hline Justiciresinol & $\overline{-}$ & -7 & -8.8 & -7.4 & -8 & $\begin{array}{l}- \\
7 . \\
4\end{array}$ & $\begin{array}{l}- \\
6 . \\
6\end{array}$ & $\begin{array}{l}- \\
6 . \\
7\end{array}$ & $\begin{array}{l}- \\
7 . \\
9\end{array}$ & $\overline{7}$ \\
\hline Kaempferol & $\overline{8}-5$ & -7.8 & -7.9 & -7.8 & -8 & $\begin{array}{l}- \\
7 . \\
4\end{array}$ & $\begin{array}{l}- \\
7 . \\
2\end{array}$ & $\begin{array}{l}- \\
7 . \\
4\end{array}$ & $\begin{array}{l}- \\
8 . \\
2\end{array}$ & $\overline{7}-8$ \\
\hline Luteolin & 9.1 & -7.9 & -8.4 & -7.4 & -8.3 & $\begin{array}{l}- \\
7 . \\
7\end{array}$ & $\begin{array}{l}- \\
7 . \\
7\end{array}$ & $\begin{array}{l}- \\
7 . \\
3\end{array}$ & -8 & $\overline{7}-$ \\
\hline $\begin{array}{l}\text { Podophyllotoxi } \\
\mathrm{n}\end{array}$ & $-\overline{8}$ & -7.9 & -8.2 & -7.6 & -7.7 & $\begin{array}{l}- \\
7 . \\
2\end{array}$ & $\begin{array}{l}- \\
8 . \\
1\end{array}$ & $\begin{array}{l}- \\
6 . \\
5\end{array}$ & $\begin{array}{l}- \\
8 . \\
4\end{array}$ & $\overline{7}$ \\
\hline Quercetin & $\begin{array}{l}- \\
9.1\end{array}$ & -7.5 & -8.2 & -7.5 & -8.4 & $\begin{array}{l}- \\
7 . \\
7\end{array}$ & $\begin{array}{l}- \\
7 . \\
6\end{array}$ & $\begin{array}{l}- \\
7 . \\
3\end{array}$ & $\begin{array}{l}- \\
8 . \\
3\end{array}$ & - \\
\hline Vasicilonone & $\begin{array}{l} \\
7.7\end{array}$ & -6.4 & -7.3 & -6.4 & -6.7 & $\begin{array}{l}- \\
6 . \\
8\end{array}$ & $\begin{array}{l}- \\
6 . \\
5\end{array}$ & $\begin{array}{l}- \\
6 . \\
2\end{array}$ & -7 & $-\overline{6}$ \\
\hline Xanthoxylol & 8.6 & -8.4 & -9.5 & -7.8 & -8.2 & $\begin{array}{l}- \\
8 . \\
6\end{array}$ & $\begin{array}{l}- \\
7 . \\
6\end{array}$ & $\begin{array}{l}- \\
7 . \\
6\end{array}$ & $\begin{array}{l}- \\
8 . \\
8\end{array}$ & -8 \\
\hline
\end{tabular}

Table 6: Docking binding affinity of FDA approved repurposed drugs against SARS-CoV 2 target proteins

Docking Binding Affinity (kcal/mol) 


\begin{tabular}{|c|c|c|c|c|c|c|c|c|c|c|c|}
\hline $\begin{array}{l}\text { S. } \\
\text { No }\end{array}$ & $\begin{array}{l}\text { Positive } \\
\text { controls }\end{array}$ & $\begin{array}{l}\text { Spi } \\
\text { ke } \\
\text { prot } \\
\text { ein }\end{array}$ & $\begin{array}{c}\text { Enve } \\
\text { lope } \\
\text { prote } \\
\text { in }\end{array}$ & $\begin{array}{c}\text { Mem } \\
\text { brane } \\
\text { protei } \\
n\end{array}$ & $\begin{array}{l}\text { Prot } \\
\text { ease }\end{array}$ & $\begin{array}{l}\text { Spik } \\
\text { e } \\
\text { prot } \\
\text { ein } \\
\text { rece } \\
\text { ptor } \\
\text { bind } \\
\text { ing } \\
\text { dom } \\
\text { ain }\end{array}$ & $\begin{array}{l}\mathrm{O} \\
\mathrm{R} \\
\mathrm{F} \\
3 \mathrm{a}\end{array}$ & $\begin{array}{l}\mathrm{N} \\
\mathrm{S} \\
\mathrm{P} \\
3\end{array}$ & $\begin{array}{l}\mathrm{N} \\
\text { sp } \\
9\end{array}$ & $\begin{array}{c}\text { Ns } \\
\mathrm{p} \\
10\end{array}$ & $\begin{array}{c}\text { Ns } \\
\mathrm{p} \\
15\end{array}$ \\
\hline & $\begin{array}{l}\text { Atovaquon } \\
\mathrm{e}\end{array}$ & -9.1 & -9.6 & -9.6 & -7.7 & -8.8 & $\begin{array}{l}- \\
8 . \\
5\end{array}$ & $\begin{array}{l}- \\
7 . \\
6\end{array}$ & $\begin{array}{l}- \\
8 . \\
8\end{array}$ & $\begin{array}{l}- \\
9 . \\
1\end{array}$ & $\begin{array}{l}- \\
9 . \\
1\end{array}$ \\
\hline & Darunavir & $\begin{array}{l}- \\
10 . \\
3\end{array}$ & -10.6 & -10.2 & -8.1 & -9.9 & $\begin{array}{l}- \\
9 . \\
7\end{array}$ & $\begin{array}{l}- \\
8 . \\
3\end{array}$ & $\begin{array}{l} \\
7 . \\
5\end{array}$ & $\begin{array}{l}- \\
8 . \\
8\end{array}$ & $\begin{array}{l}- \\
8 . \\
8\end{array}$ \\
\hline & $\begin{array}{l}\text { dexamethas } \\
\text { one }\end{array}$ & -5.8 & -7.7 & -9.4 & -6.9 & -5.3 & $\begin{array}{l}- \\
7 . \\
3\end{array}$ & $\begin{array}{l}- \\
4 . \\
9\end{array}$ & $\begin{array}{l}- \\
6 . \\
7\end{array}$ & $\begin{array}{l}- \\
8 . \\
5\end{array}$ & $\begin{array}{l}- \\
8 . \\
5\end{array}$ \\
\hline & $\begin{array}{l}\text { Hydroxychl } \\
\text { oroquine }\end{array}$ & -8.2 & -6.3 & -6.7 & -5.4 & $\begin{array}{l}- \\
10.1\end{array}$ & $\begin{array}{l}- \\
6 . \\
1\end{array}$ & $\begin{array}{l}- \\
7 . \\
9\end{array}$ & $\begin{array}{l}- \\
5 . \\
5\end{array}$ & $\begin{array}{l}- \\
6 . \\
9\end{array}$ & $\begin{array}{l}- \\
6 . \\
9\end{array}$ \\
\hline & ivermectin & -8.9 & -8.8 & -9.2 & -7.3 & -8.8 & $\begin{array}{l}- \\
8 . \\
6\end{array}$ & $\begin{array}{l}- \\
8 . \\
2 \\
\end{array}$ & $\begin{array}{l}- \\
7 . \\
4\end{array}$ & $\begin{array}{l}- \\
10 \\
.3 \\
\end{array}$ & $\begin{array}{l}- \\
10 \\
.3 \\
\end{array}$ \\
\hline & Nelfinavir & -8.5 & -9.6 & -9.3 & -8.2 & -8.3 & $\begin{array}{l}- \\
8 . \\
6\end{array}$ & $\begin{array}{l}- \\
6 . \\
9\end{array}$ & $\begin{array}{l} \\
7 . \\
2\end{array}$ & $\begin{array}{l}- \\
9 . \\
5\end{array}$ & $\begin{array}{l}- \\
9 . \\
5\end{array}$ \\
\hline & Ouabain & -9.6 & -8.2 & -8.6 & -7.7 & -8.7 & $\begin{array}{l}- \\
8 . \\
9\end{array}$ & $\begin{array}{l}- \\
7 . \\
3\end{array}$ & -7 & $\begin{array}{l}- \\
9 . \\
6\end{array}$ & $\begin{array}{l}- \\
9 . \\
6\end{array}$ \\
\hline & remedevsir & -10 & -8.2 & -8.2 & -8 & -9 & $\begin{array}{l}- \\
8 . \\
3\end{array}$ & $\begin{array}{l}- \\
8 . \\
2\end{array}$ & $\begin{array}{l}- \\
6 . \\
9\end{array}$ & $\begin{array}{l}- \\
9 . \\
1\end{array}$ & $\begin{array}{l}- \\
9 . \\
1\end{array}$ \\
\hline & Saquinavir & -8.7 & -9.6 & -9.8 & -8.6 & -7.7 & $\begin{array}{l}- \\
9 . \\
5\end{array}$ & $\begin{array}{l}- \\
7 . \\
4\end{array}$ & $\begin{array}{l}- \\
7 . \\
8\end{array}$ & $\begin{array}{l}- \\
10 \\
.4\end{array}$ & $\begin{array}{l}- \\
10 \\
.4\end{array}$ \\
\hline & Favipiravir & -6.1 & -4.7 & -5.6 & -4.8 & -6.8 & $\begin{array}{l}- \\
5 . \\
4\end{array}$ & -6 & $\begin{array}{l}- \\
4 . \\
6\end{array}$ & $\begin{array}{l}- \\
6 . \\
3 \\
\end{array}$ & $\begin{array}{l}- \\
4 . \\
9\end{array}$ \\
\hline
\end{tabular}


Table 7: Protein-ligand interaction of top-scoring compounds

\begin{tabular}{|c|c|c|c|c|c|c|}
\hline \multirow[b]{2}{*}{$\begin{array}{l}\text { S. } \\
\text { N } \\
\text { o. }\end{array}$} & \multirow[b]{2}{*}{ Protein } & \multirow[b]{2}{*}{$\begin{array}{l}\text { PD } \\
\text { B } \\
\text { ID }\end{array}$} & \multirow[b]{2}{*}{ Ligand } & \multirow{2}{*}{$\begin{array}{l}\text { Bind } \\
\text { ing } \\
\text { affin } \\
\text { ity } \\
\text { (kcal } \\
/ \mathrm{mol} \\
)\end{array}$} & \multicolumn{2}{|c|}{$\begin{array}{c}\text { Amino acid residues } \\
\text { involved and distance }(\square)\end{array}$} \\
\hline & & & & & $\begin{array}{c}\text { Hydrogen } \\
\text { bonding }\end{array}$ & $\begin{array}{l}\text { Hydropho } \\
\text { bic } \\
\text { interaction } \\
\mathrm{s}\end{array}$ \\
\hline 1 & Spike protein & $\begin{array}{l}6 \mathrm{C} \\
\mathrm{R} \\
\mathrm{V}\end{array}$ & Quercetin & $\begin{array}{l}- \\
9.1\end{array}$ & $\begin{array}{l}\text { 535B THR } \\
(1.97), 722 \mathrm{C} \\
\text { MET (1.93), } \\
\text { 727C ASP } \\
(2.30), 957 \mathrm{C} \\
\text { SER (3.32), } \\
\text { 959C LEU } \\
(2.93), 960 \mathrm{C} \\
\text { ASN (2.70), } \\
\text { 982C ARG } \\
\text { (1.97), 982C } \\
\text { ARG (2.26) }\end{array}$ & $\begin{array}{l}\text { 558B PHE } \\
(3.59), \\
558 \mathrm{~B} \text { PHE } \\
(3.75), \\
837 \mathrm{C} \text { PHE } \\
(4.00), \\
\text { 948C LEU } \\
(3.93)\end{array}$ \\
\hline 2 & $\begin{array}{l}\text { Envelope } \\
\text { protein }\end{array}$ & $\begin{array}{l}5 X \\
29\end{array}$ & Xanthoxylol & $-\overline{8} \cdot$ & $\begin{array}{l}\text { 35A THR } \\
\text { (3.36), 35A } \\
\text { THR (3.13), } \\
\text { 61D ARG } \\
\text { (3.26), 61D } \\
\text { ARG (2.65), } \\
\text { 64D ASN } \\
(2.94), 64 \mathrm{D} \\
\text { ASN (2.37) }\end{array}$ & $\begin{array}{l}\text { 31 A LEU } \\
(3.89), \\
47 \mathrm{E} \text { VAL } \\
(3.57), \\
49 \mathrm{E} \text { VAL } \\
(3.70), \\
57 \mathrm{E} \text { TYR } \\
(3.62), \\
57 \mathrm{E} \text { TYR } \\
(3.57), \\
57 \mathrm{E} \text { TYR } \\
(3.77), \\
57 \mathrm{E} \text { TYR } \\
(3.77)\end{array}$ \\
\hline
\end{tabular}




\begin{tabular}{|c|c|c|c|c|c|c|}
\hline 3 & $\begin{array}{l}\text { Membrane } \\
\text { protein }\end{array}$ & $\begin{array}{l}316 \\
G\end{array}$ & Xanthoxylol & $\overline{9} .5$ & $\begin{array}{l}\text { 26B TYR } \\
(1.82), 52 \mathrm{~B} \\
\text { SER (3.39), } \\
\text { 67B TYR } \\
(2.23)\end{array}$ & $\begin{array}{l}\text { 63B TYR } \\
\text { (3.91), } \\
\text { 65B LEU } \\
(3.87), \\
\text { 235A } \\
\text { PRO } \\
(3.76)\end{array}$ \\
\hline 4 & Main protease & $\begin{array}{l}6 \mathrm{~L} \\
\mathrm{U} 7\end{array}$ & $\begin{array}{l}\text { Chinensinap } \\
\text { hthol methyl } \\
\text { ether }\end{array}$ & -8 & $\begin{array}{l}26 \mathrm{~A} \text { THR } \\
(2.98), 143 \mathrm{~A} \\
\text { GLY (2.28), } \\
\text { 166A GLU } \\
(2.15)\end{array}$ & $\begin{array}{l}165 \mathrm{~A} \\
\text { MET } \\
(3.81)\end{array}$ \\
\hline 5 & $\begin{array}{l}\text { Spike protein } \\
\text { receptor binding } \\
\text { domain }\end{array}$ & $\begin{array}{l}6 \\
\mathrm{M} \\
0 \mathrm{~J}\end{array}$ & $\begin{array}{l}\text { Chinensinap } \\
\text { hthol methyl } \\
\text { ether }\end{array}$ & $-\overline{8}$ & $\begin{array}{l}\text { 98A GLN } \\
(2.23), 196 \mathrm{~A} \\
\text { TYR (3.09), } \\
\text { 196A TYR } \\
\text { (2.38), 205A } \\
\text { GLY (3.05), } \\
\text { 206A ASP } \\
\text { (3.27), 210A } \\
\text { ASN (2.24), } \\
\text { 562A LYS } \\
\text { (2.49) }\end{array}$ & $\begin{array}{l}95 \mathrm{~A} \text { LEU } \\
(3.67), \\
102 \mathrm{~A} \\
\text { GLN } \\
(3.63), \\
210 \mathrm{~A} \\
\text { ASN } \\
(3.77)\end{array}$ \\
\hline 6 & ORF 3a & $\begin{array}{l}6 \mathrm{X} \\
\mathrm{D} \\
\mathrm{C}\end{array}$ & Xanthoxylol & $\overline{8} 8$ & $\begin{array}{l}\text { 66B LYS } \\
(2.28), 122 \mathrm{~A} \\
\text { ARG }(2.22), \\
\text { 122A ARG } \\
(1.97), 205 \mathrm{~A} \\
\text { SER (1.91) }\end{array}$ & $\begin{array}{l}206 \mathrm{~A} \\
\text { TYR } \\
(3.52), \\
206 \mathrm{~A} \\
\text { TYR } \\
(3.67) \text {, } \\
\text { 207A PHE } \\
\text { (3.96), } \\
\text { 207A PHE } \\
\text { (3.63) }\end{array}$ \\
\hline 7 & Nsp 3 & $\begin{array}{l}6 \\
\text { W } \\
X \\
D\end{array}$ & $\begin{array}{l}\text { Podophyllot } \\
\text { oxin }\end{array}$ & $\overline{8} 8$ & $\begin{array}{l}\text { 23A ILE } \\
(2.18), 126 \mathrm{~A} \\
\text { LEU }(2.27)\end{array}$ & $\begin{array}{l}\text { 23A ILE } \\
(3.63), \\
126 \mathrm{~A} \\
\text { LEU } \\
\text { (3.74), } \\
\text { 156A PHE } \\
(3.58),\end{array}$ \\
\hline
\end{tabular}




\begin{tabular}{|c|c|c|c|c|c|c|}
\hline & & & & & & $\begin{array}{l}\text { 160A } \\
\text { LEU } \\
(3.95)\end{array}$ \\
\hline 8 & Nsp 9 & $\begin{array}{l}2 \mathrm{G} \\
9 \mathrm{~T}\end{array}$ & Xanthoxylol & - & $\begin{array}{l}\text { 59A SER } \\
(1.95)\end{array}$ & $\begin{array}{l}\text { 40A PHE } \\
(3.68), \\
56 \mathrm{~A} \text { PHE } \\
(3.46), \\
\text { 65A ILE } \\
(3.95)\end{array}$ \\
\hline 9 & Nsp 10 & $\begin{array}{l}6 \mathrm{~V} \\
\mathrm{~W} \\
\mathrm{~W}\end{array}$ & Xanthoxylol & $-\overline{8.8}$ & $\begin{array}{l}18 \mathrm{~L} \text { ALA } \\
(3.16), 80 \mathrm{E} \\
\text { HIS }(2.31)\end{array}$ & $\begin{array}{l}\text { 71E ALA } \\
(3.50)\end{array}$ \\
\hline $\begin{array}{l}1 \\
0\end{array}$ & Nsp 15 & $\begin{array}{l}6 \mathrm{~V} \\
\mathrm{XS}\end{array}$ & Apigenin & -8 & $\begin{array}{l}\text { 15B HIS } \\
(2.46), 64 \mathrm{~B} \\
\text { ILE }(2.42) \text {, } \\
\text { 102B VAL } \\
(2.02)\end{array}$ & $\begin{array}{l}\text { 102B } \\
\text { VAL } \\
(3.80)\end{array}$ \\
\hline
\end{tabular}

Table 8 Binding interaction of protein-ligand complexes against SARS-CoV 2 target proteins

\begin{tabular}{|c|c|c|c|c|c|c|}
\hline \multirow[t]{2}{*}{$\begin{array}{l}\text { S.N } \\
\text { o. }\end{array}$} & \multirow[t]{2}{*}{$\begin{array}{c}\text { Protein- } \\
\text { phytocompo } \\
\text { und complex }\end{array}$} & \multirow{2}{*}{$\begin{array}{l}\text { Binding } \\
\text { affinity } \\
\text { (kcal/m } \\
\text { ol) }\end{array}$} & \multirow[t]{2}{*}{$\begin{array}{l}\text { Protein-drug } \\
\text { complex }\end{array}$} & \multirow{2}{*}{$\begin{array}{c}\text { Bindin } \\
\mathrm{g} \\
\text { affinity } \\
(\mathrm{kcal} / \mathrm{m} \\
\mathrm{ol})\end{array}$} & \multicolumn{2}{|c|}{$\begin{array}{l}\text { phytocompounds } \\
\text { and FDA approved } \\
\text { COVID drugs }\end{array}$} \\
\hline & & & & & $\begin{array}{l}\text { Hydro } \\
\text { gen } \\
\text { bondin } \\
\text { g }\end{array}$ & $\begin{array}{l}\text { Hydroph } \\
\text { obic } \\
\text { interactio } \\
\text { ns }\end{array}$ \\
\hline 1 & $\begin{array}{l}\text { Membrane } \\
\text { protein- } \\
\text { Xanthoxylol }\end{array}$ & -9.5 & $\begin{array}{l}\text { Membrane } \\
\text { protein- } \\
\text { Darunavir }\end{array}$ & -10.3 & $\begin{array}{l}26 \mathrm{~B} \\
\mathrm{TYR}\end{array}$ & $\begin{array}{l}\text { 63B } \\
\text { TYR } \\
235 \mathrm{~A} \\
\text { PRO }\end{array}$ \\
\hline 4 & $\begin{array}{l}\text { Main } \\
\text { protease- } \\
\text { Chinensinap } \\
\text { hthol methyl }\end{array}$ & -8 & $\begin{array}{l}\text { Main protease- } \\
\text { Saquinavir }\end{array}$ & -8.6 & $\begin{array}{l}143 \mathrm{~A} \\
\text { GLY, } \\
166 \mathrm{~A} \\
\text { GLU }\end{array}$ & $\begin{array}{l}165 \mathrm{~A} \\
\mathrm{MET}\end{array}$ \\
\hline
\end{tabular}




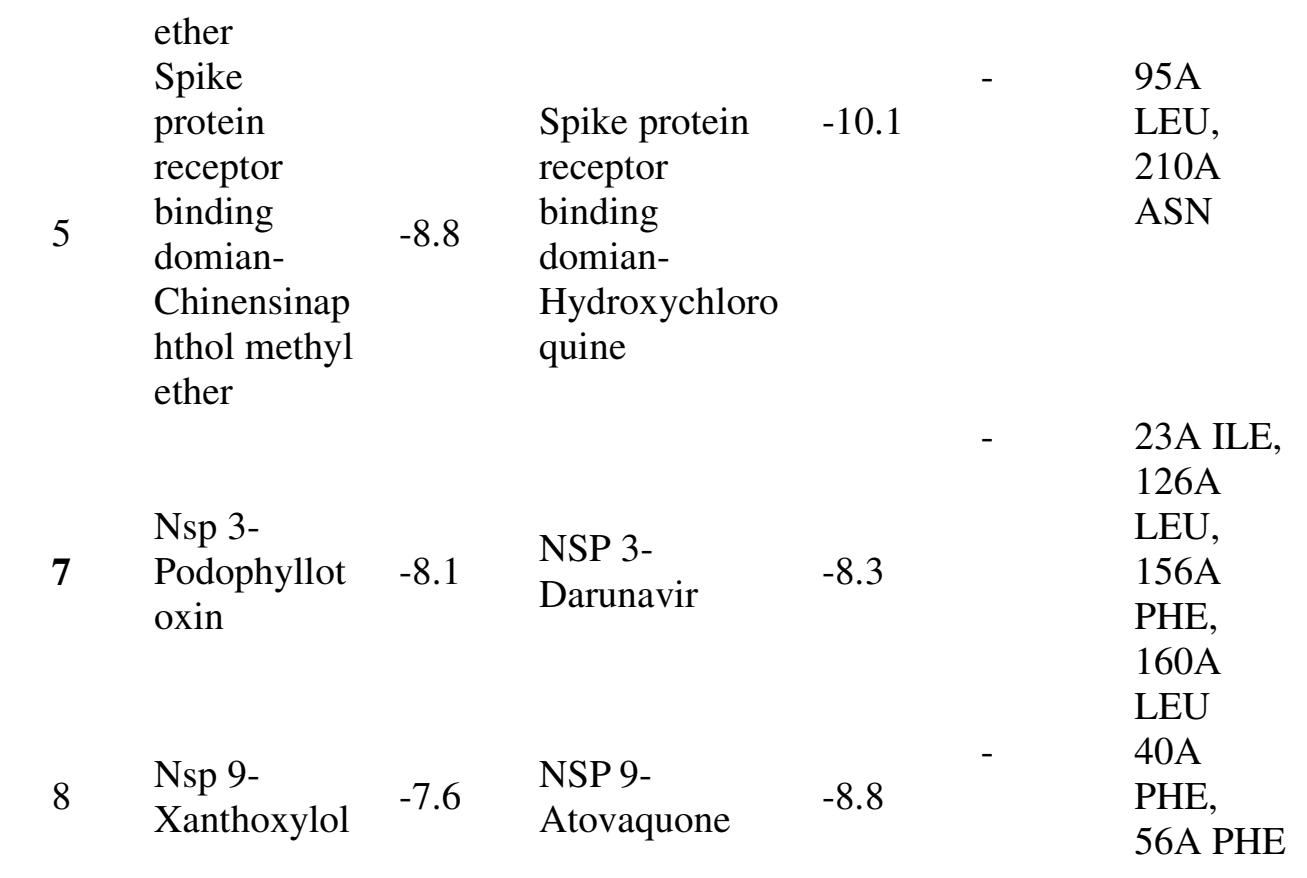

Table 9: ADME/T properties of the screened phytocompounds

\begin{tabular}{|c|c|c|c|c|c|c|c|c|c|}
\hline \multirow{3}{*}{$\begin{array}{l}\text { S. } \\
\text { N } \\
\text { O. }\end{array}$} & \multirow{3}{*}{ COMPOUND } & \multicolumn{2}{|c|}{$\begin{array}{c}\text { ABSORPT } \\
\text { ION }\end{array}$} & \begin{tabular}{|c|} 
DISTRI \\
BUTIO \\
$\mathrm{N}$ \\
\end{tabular} & \multicolumn{2}{|c|}{$\begin{array}{c}\text { METABO } \\
\text { LISM }\end{array}$} & $\begin{array}{c}\text { EXC } \\
\text { RETI } \\
\text { ON }\end{array}$ & \multicolumn{2}{|c|}{$\begin{array}{c}\text { TOXICIT } \\
\mathrm{Y}\end{array}$} \\
\hline & & $\begin{array}{c}\text { Wat } \\
\text { er } \\
\text { solu } \\
\text { bilit } \\
\text { y }\end{array}$ & $\begin{array}{c}\text { Inte } \\
\text { stina } \\
1 \\
\text { abso } \\
\text { rptio } \\
\text { n } \\
\text { (hu } \\
\text { man } \\
\text { ) } \\
\end{array}$ & $\begin{array}{l}\text { BBB } \\
\text { Perme } \\
\text { ability }\end{array}$ & $\begin{array}{c}\text { CY } \\
\text { P3 } \\
\text { A4 } \\
\text { sub } \\
\text { stra } \\
\text { te }\end{array}$ & $\begin{array}{c}\text { CY } \\
\text { P3 } \\
\text { A4 } \\
\text { inh } \\
\text { bitc } \\
\text { r }\end{array}$ & $\begin{array}{c}\text { Total } \\
\text { cleara } \\
\text { nce }\end{array}$ & $\begin{array}{c}\text { Max } \\
\cdot \\
\text { Tole } \\
\text { rate } \\
\text { d } \\
\text { dose } \\
\text { (hu } \\
\text { man } \\
\text { ) }\end{array}$ & $\begin{array}{l}\text { Or } \\
\text { al } \\
\text { rat } \\
\text { acu } \\
\text { te } \\
\text { tox } \\
\text { icit } \\
\text { y }\end{array}$ \\
\hline & & 急 & 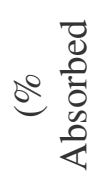 & 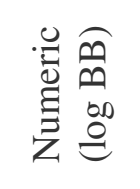 & $e_{0}^{\infty}$ & 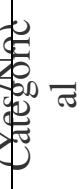 & 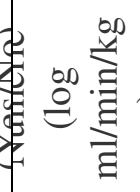 & 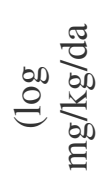 & 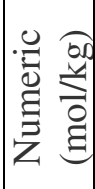 \\
\hline 1. & 3',4'- & - & 94.8 & -0.199 & No & No & 0.731 & 0.31 & 1.9 \\
\hline
\end{tabular}




\begin{tabular}{|c|c|c|c|c|c|c|c|c|c|}
\hline & $\begin{array}{l}\text { dihydroxyflavo } \\
\text { nol }\end{array}$ & $\begin{array}{l}1.1 \\
37 \\
\end{array}$ & 75 & & & & & 4 & 9 \\
\hline 2. & Apigenin & $\begin{array}{l}- \\
3.3 \\
8\end{array}$ & $\begin{array}{l}91.5 \\
66\end{array}$ & -0.903 & No & No & 0.595 & $\begin{array}{l}0.33 \\
7\end{array}$ & $\begin{array}{l}1.9 \\
78\end{array}$ \\
\hline 3. & $\begin{array}{l}\text { Chinensinaphth } \\
\text { ol methyl ether }\end{array}$ & $\begin{array}{l}- \\
4.7 \\
16\end{array}$ & 100 & -0.961 & Yes & No & 0.461 & $\begin{array}{l}0.30 \\
7\end{array}$ & $\begin{array}{l}3.0 \\
53\end{array}$ \\
\hline 4. & $\begin{array}{l}\text { Heliobuphthalm } \\
\text { in }\end{array}$ & $\begin{array}{l}- \\
4.6 \\
63\end{array}$ & 100 & -1.118 & Yes & Yes & 0.057 & $\begin{array}{l}0.48 \\
9\end{array}$ & $\begin{array}{l}2.7 \\
47\end{array}$ \\
\hline 5. & Isolariciresinol & $\begin{array}{l}- \\
3.0 \\
4\end{array}$ & $\begin{array}{l}74.2 \\
9\end{array}$ & -0.939 & No & No & 0.477 & $\begin{array}{l}0.53 \\
1\end{array}$ & $\begin{array}{l}2.4 \\
49\end{array}$ \\
\hline 6. & Justiciresinol & $\begin{array}{l}- \\
4.6 \\
18 \\
\end{array}$ & $\begin{array}{l}71.7 \\
91\end{array}$ & -1.038 & Yes & Yes & 0.176 & $\begin{array}{l}0.27 \\
6\end{array}$ & $\begin{array}{l}2.1 \\
09\end{array}$ \\
\hline 7. & Kaempferol & $\begin{array}{l}- \\
3.2 \\
82\end{array}$ & $\begin{array}{l}80.0 \\
64\end{array}$ & -1.065 & No & No & 0.496 & $\begin{array}{l}0.77 \\
4\end{array}$ & $\begin{array}{l}2.1 \\
97\end{array}$ \\
\hline 8. & Luteolin & $\begin{array}{l}- \\
3.2 \\
94\end{array}$ & $\begin{array}{l}82.1 \\
75\end{array}$ & -1.145 & No & Yes & 0.568 & $\begin{array}{l}0.56 \\
4\end{array}$ & $\begin{array}{l}2.4 \\
53\end{array}$ \\
\hline 9. & $\begin{array}{l}\text { Podophyllotoxi } \\
\text { n }\end{array}$ & $\begin{array}{l}- \\
3.9 \\
71\end{array}$ & 100 & -0.821 & Yes & Yes & 0.205 & $\begin{array}{l}- \\
0.45\end{array}$ & $\begin{array}{l}2.5 \\
12\end{array}$ \\
\hline 10 & Quercetin & $\begin{array}{l}- \\
3.2 \\
82 \\
\end{array}$ & $\begin{array}{l}80.0 \\
64\end{array}$ & -1.065 & No & No & 0.496 & $\begin{array}{l}0.77 \\
4\end{array}$ & $\begin{array}{l}2.1 \\
97\end{array}$ \\
\hline 11 & Vasicilonone & $\begin{array}{l}- \\
2.9 \\
25\end{array}$ & $\begin{array}{l}77.2 \\
07\end{array}$ & -1.098 & No & No & 0.407 & $\begin{array}{l}0.49 \\
9\end{array}$ & $\begin{array}{l}2.4 \\
71\end{array}$ \\
\hline 12 & Xanthoxylol & $\begin{array}{l}- \\
3.6 \\
88\end{array}$ & $\begin{array}{l}94.7 \\
56\end{array}$ & -0.578 & Yes & Yes & $\begin{array}{l}- \\
0.046\end{array}$ & $\begin{array}{l}- \\
0.58 \\
3\end{array}$ & $\begin{array}{l}2.2 \\
11\end{array}$ \\
\hline
\end{tabular}

Table 10: Prediction of Activity Spectra for Substances (PASS) for lead S.No. compounds
Compound
Antiviral 
1. 3',4'-Dihydroxyflavonol

2. Apigenin

3. Chinensinaphthol methyl ether

4. Heliobuphthalmin

5. Isolariciresinol

6. Justiciresinol

7. Kaempferol

8. Luteolin

9. Podophyllotoxin

10. Quercetin

11. Vasicilonone

12. Xanthoxylol
Adeno

Virus

$\begin{array}{llllllll}\mathrm{Pa} & \mathrm{Pi} & \mathrm{Pa} & \mathrm{Pi} & \mathrm{Pa} & \mathrm{Pi} & \mathrm{Pa} & \mathrm{Pi}\end{array}$

$\begin{array}{llllllll}0.259 & 0.128 & 0.184 & 0.038 & 0.291 & 0.095 & 0.416 & 0.013\end{array}$

$\begin{array}{lllllllll}0.301 & 0.088 & 0.135 & 0.085 & 0.459 & 0.030 & 0.469 & 0.007\end{array}$

$\begin{array}{lllllllll}0.228 & 0.167 & - & - & 0.204 & 0.191 & 0.206 & 0.046\end{array}$

$\begin{array}{llllllll}0.339 & 0.060 & 0.225 & 0.021 & 0.253 & 0.128 & 0.172 & 0.130\end{array}$

$\begin{array}{lllllllll}0.216 & 0.184 & - & - & 0.262 & 0.120 & 0.255 & 0.049\end{array}$

$\begin{array}{llllllll}- & - & 0.200 & 0.030 & 0.332 & 0.072 & 0.276 & 0.040\end{array}$

$\begin{array}{llllllll}0.246 & 0.143 & 0.164 & 0.051 & 0.400 & 0.047 & 0.496 & 0.005\end{array}$

$\begin{array}{llllllll}0.246 & 0.143 & 0.149 & 0.067 & 0.462 & 0.030 & 0.437 & 0.006\end{array}$

$\begin{array}{lllllllll}0 . & - & - & - & & 0.209 & 0.183 & 0.190 & 0.099\end{array}$

$\begin{array}{llllllll}- & - & 0.170 & 0.047 & 0.403 & 0.046 & 0.498 & 0.005\end{array}$

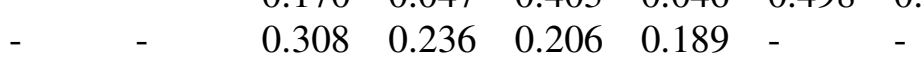

$\begin{array}{llllllll}0.290 & 0.097 & - & - & 0.422 & 0.040 & 0.228 & 0.063\end{array}$

Pa- Probability of molecule to be active; Pi- Probability of molecule to be inactive

\section{Supplementary information}

Table S1: List of phytocompounds from Justicia adhatoda

\begin{tabular}{|l|l|}
\hline S.No. & Name of phytocompounds \\
\hline 1. & Vasicine \\
\hline 2. & Vasicinone \\
\hline 3. & adhatodine \\
\hline 4. & Vasicinolone \\
\hline 5. & vasicol \\
\hline 6. & vasicoline \\
\hline 7. & vasicolinone \\
\hline 8. & 2-acetyl benzyl amine \\
\hline 9. & Anisotine \\
\hline 10. & $\beta$-sitosterol \\
\hline 11. & tritricontane \\
\hline 12. & $\alpha$-amyrin \\
\hline 13. & apigenin \\
\hline 14. & astragalin \\
\hline 15. & Kaempferol \\
\hline 16. & quercetin \\
\hline
\end{tabular}




\begin{tabular}{|c|c|}
\hline 17. & vitexin \\
\hline 18. & 9-acetamido-3,4dihydropyrido-(3,4-b) indole \\
\hline 19. & Amino-n-butyric acid \\
\hline 20. & Betaine \\
\hline 21. & $\beta$-carotene \\
\hline 22. & Daucosterol \\
\hline 23. & Deoxyvasicine \\
\hline 24. & Deoxyvasicinone \\
\hline 25. & Violanthin \\
\hline 26. & Vasnetine \\
\hline 27. & Desmethoxyaniflorine \\
\hline 28. & Rhamnoxylvitexin \\
\hline 29. & 2"-O-xylosylvitexin \\
\hline 30. & Isovitexin \\
\hline 31. & 3-hydroxyanisotine \\
\hline 32. & Epitaraxerol \\
\hline 33. & 2',4-dihydroxychalcone4-O- $\beta$-D glucopyranoside \\
\hline 34. & 5-hydroxy vasicine \\
\hline 35. & Luteolin \\
\hline 36. & umbeliferone \\
\hline 37. & 3',4'-Dihydroxyflavonol \\
\hline 38. & Kaempferitrin \\
\hline 39. & 10H-Quindoline \\
\hline 40. & Jusbetonin \\
\hline 41. & Allantoin \\
\hline 42. & Taiwanin E \\
\hline 43. & Taiwanin E methyl ether \\
\hline 44. & Justicidin E \\
\hline 45. & Isolariciresinol \\
\hline 46. & Justiciresinol \\
\hline 47. & Xanthoxylol \\
\hline 48. & Podophyllotoxin \\
\hline 49. & Heliobuphthalmin \\
\hline 50. & Sesamin \\
\hline 51. & Chinensinaphthol methyl ether \\
\hline 52. & Justalakonin \\
\hline
\end{tabular}




\begin{tabular}{|l|l|}
\hline 53. & Cleistanthin B \\
\hline 54. & Patentiflorin A \\
\hline 55. & Patentiflorin B \\
\hline 56. & Tuberculatin \\
\hline 57. & Glyodin \\
\hline 58. & Vasakin \\
\hline 59. & Helioxanthin \\
\hline 60. & Justicidin B \\
\hline 61. & Diphyllin \\
\hline 62. & Justicidin A \\
\hline 63. & Justicidinoside A \\
\hline 64. & Justicidinoside C \\
\hline 65. & Justicidinoside B \\
\hline 66. & Elenoside \\
\hline 67. & Diphylin apioside \\
\hline 68. & Diphyllin apioside-5-acetate \\
\hline 69. & 4'-Dimethyl chinensis naphthol methyl ether \\
\hline 70. & 3-methylheptanone \\
\hline 71. & 3-hydroxy-oleannane-5ene \\
\hline 72. & 37-hydroxyhentetracontan-19-one \\
\hline 73. & 37-hydroxyhexatetracont-1-en-15one \\
\hline 74. & Hydroxyl oxychalcone \\
\hline 75. & 3a-hydroxy-D-friedoolean-5-ene \\
\hline 76. & 2'-glucosyl-4-hydroxyloxychalcone \\
\hline 77. & 7-methoxy-vasicinone \\
\hline 78. & 7-Methoxyvasicinone hydrate \\
\hline 79. & 5-methoxyvasicinone \\
\hline 80. & Maiontone \\
\hline 81. & Vasinol \\
\hline 82. & Adhatodic acid \\
\hline 83. & vasicinine \\
\hline 84. & 6-hydroxy Pegamine \\
\hline 85. & Adhavasinone \\
\hline 86. & 1,2,3,9-tetrahydro-5methoxy-pyrrolo[2,1b] \\
\hline 87. & vuinazoline-3-ol \\
\hline
\end{tabular}


Table S2: Phytocompounds with structure in PubChemdatabase

\begin{tabular}{|c|c|}
\hline S.No. & Name of phytocompounds \\
\hline 1. & 10h-quindoline \\
\hline 2. & 2',4-dihydroxychalcone4-O- $\beta$-D glucopyranoside \\
\hline 3. & 2-acetyl benzyl amine \\
\hline 4. & 2"-O-xylosylvitexin \\
\hline 5. & 3',4'-dihydroxyflavonol \\
\hline 6. & 3-hydroxyanisotine \\
\hline 7. & 5-hydroxy vasicine \\
\hline 8. & 9-acetamido-3,4dihydropyrido-(3,4-b) indole \\
\hline 9. & Adhatodine \\
\hline 10 . & Allantoin \\
\hline 11. & Amino-n-butyric acid \\
\hline 12. & Anisotine \\
\hline 13. & Apigenin \\
\hline 14. & Astragalin \\
\hline 15. & Betaine \\
\hline 16. & Chinensinaphthol methyl ether \\
\hline 17. & Cleistanthin B \\
\hline 18. & Daucosterol \\
\hline 19. & Deoxyvasicine \\
\hline 20. & Deoxyvasicinone \\
\hline 21. & Desmethoxyaniflorine \\
\hline 22. & Diphylin apioside \\
\hline 23. & Diphyllin \\
\hline 24. & Diphyllin apioside-5-acetate \\
\hline 25. & Elenoside \\
\hline 26. & Epitaraxerol \\
\hline 27. & Glyodin \\
\hline 28. & Heliobuphthalmin \\
\hline 29. & Helioxanthin \\
\hline 30. & Isolariciresinol \\
\hline 31. & Isovitexin \\
\hline 32. & Jusbetonin \\
\hline 33. & Justalakonin \\
\hline
\end{tabular}




\begin{tabular}{|c|c|}
\hline 34. & Justicidin A \\
\hline 35. & Justicidin B \\
\hline 36. & Justicidin E \\
\hline 37. & Justicidinoside A \\
\hline 38. & Justicidinoside B \\
\hline 39. & Justicidinoside C \\
\hline 40. & Justiciresinol \\
\hline 41. & Kaempferitrin \\
\hline 42. & Kaempferol \\
\hline 43. & Luteolin \\
\hline 44. & Patentiflorin A \\
\hline 45. & Patentiflorin B \\
\hline 46. & Podophyllotoxin \\
\hline 47. & Quercetin \\
\hline 48. & Rhamnoxylvitexin \\
\hline 49. & Sesamin \\
\hline 50. & Taiwanin E \\
\hline 51. & Taiwanin E methyl ether \\
\hline 52. & Tritricontane \\
\hline 53. & Tuberculatin \\
\hline 54. & Umbeliferone \\
\hline 55. & Vasakin \\
\hline 56. & Vasicine \\
\hline 57. & Vasicinolone \\
\hline 58. & Vasicinone \\
\hline 59. & Vasicol \\
\hline 60. & Vasicoline \\
\hline 61. & Vasicolinone \\
\hline 62. & Vasnetine \\
\hline 63. & Violanthin \\
\hline 64. & Vitexin \\
\hline 65. & Xanthoxylol \\
\hline 66. & A-amyrin \\
\hline 67. & B-carotene \\
\hline 68. & B-sitosterol \\
\hline
\end{tabular}


Table S3: ADME/T properties of phytocompounds (Docking affinity less than or equal to $-7 \mathrm{kcal} / \mathrm{mol}$ )

\begin{tabular}{|c|c|c|c|c|c|c|c|c|c|}
\hline \multirow[b]{3}{*}{$\begin{array}{l}\text { S. } \\
\text { N } \\
\text { o. }\end{array}$} & \multirow[b]{3}{*}{ Compound } & \multicolumn{2}{|c|}{ Absorption } & \multirow{2}{*}{$\begin{array}{c}\begin{array}{c}\text { Distr } \\
\text { ibuti } \\
\text { on }\end{array} \\
\begin{array}{c}\text { BBB } \\
\text { Perm } \\
\text { eabil } \\
\text { ity }\end{array}\end{array}$} & \multicolumn{2}{|c|}{ Metabolism } & \multirow{2}{*}{$\begin{array}{l}\text { Excr } \\
\text { etion }\end{array}$} & \multicolumn{2}{|c|}{ Toxicity } \\
\hline & & $\begin{array}{l}\text { Wat } \\
\text { er } \\
\text { solu } \\
\text { bilit } \\
\text { y }\end{array}$ & $\begin{array}{l}\text { Intes } \\
\text { tinal } \\
\text { absor } \\
\text { ption } \\
\text { (hum } \\
\text { an) }\end{array}$ & & $\begin{array}{l}\text { CYP } \\
3 \text { A4 } \\
\text { subst } \\
\text { rate }\end{array}$ & $\begin{array}{l}\text { CYP } \\
3 \mathrm{~A} 4 \\
\text { inhibi } \\
\text { tor }\end{array}$ & & $\begin{array}{l}\text { Max. } \\
\text { Toler } \\
\text { ated } \\
\text { dose } \\
\text { (hum } \\
\text { an) }\end{array}$ & $\begin{array}{c}\text { Oral } \\
\text { rat } \\
\text { acut } \\
\text { e } \\
\text { toxi } \\
\text { city }\end{array}$ \\
\hline & & $\begin{array}{c}\mathrm{N} \\
\mathrm{u} \\
\mathrm{m} \\
\mathrm{er} \\
\mathrm{ic} \\
(1 \\
\mathrm{o} \\
\mathrm{g} \\
\mathrm{m} \\
\mathrm{ol} \\
/ \mathrm{L} \\
)\end{array}$ & $\begin{array}{l}\mathrm{Nu} \\
\text { me } \\
\text { ric } \\
\text { (\% } \\
\mathrm{Ab} \\
\text { sor } \\
\text { be } \\
\text { d) }\end{array}$ & $\begin{array}{l}\mathrm{N} \\
\mathrm{u} \\
\mathrm{m} \\
\mathrm{eri} \\
\mathrm{c} \\
(\mathrm{lo} \\
\mathrm{g} \\
\mathrm{B} \\
\mathrm{B})\end{array}$ & $\begin{array}{c}\text { Cat } \\
\text { eg } \\
\text { ori } \\
\text { cal } \\
\text { (Y } \\
\text { es/ } \\
\text { No } \\
\text { ) }\end{array}$ & $\begin{array}{c}\text { Cat } \\
\text { eg } \\
\text { ori } \\
\text { cal } \\
\text { (Y } \\
\text { es/ } \\
\text { No } \\
\text { ) }\end{array}$ & $\begin{array}{c}\mathrm{Nu} \\
\mathrm{me} \\
\mathrm{ric} \\
(\mathrm{lo} \\
\mathrm{g} \\
\mathrm{ml} / \\
\mathrm{mi} \\
\mathrm{n} / \mathrm{k} \\
\mathrm{g})\end{array}$ & $\begin{array}{c}\mathrm{Nu} \\
\mathrm{me} \\
\mathrm{ric} \\
(\mathrm{lo} \\
\mathrm{g} \\
\mathrm{mg} \\
/ \mathrm{kg} \\
/ \mathrm{da} \\
\mathrm{y})\end{array}$ & $\begin{array}{c}\mathrm{N} \\
\mathrm{u} \\
\mathrm{m} \\
\mathrm{er} \\
\mathrm{ic} \\
( \\
\mathrm{m} \\
\mathrm{ol} \\
/ \mathrm{k} \\
\mathrm{g})\end{array}$ \\
\hline 1. & $\begin{array}{l}\text { 10h- } \\
\text { quindoline }\end{array}$ & $\begin{array}{l}- \\
4.85 \\
2\end{array}$ & $\begin{array}{l}94.4 \\
87\end{array}$ & $\begin{array}{l}0.34 \\
9\end{array}$ & Yes & Yes & 0.797 & $\begin{array}{l}- \\
0.124\end{array}$ & $\begin{array}{l}2.29 \\
8\end{array}$ \\
\hline 2. & $\begin{array}{l}\text { 3',4'- } \\
\text { dihydroxyfla } \\
\text { vonol }\end{array}$ & $\begin{array}{l}- \\
1.13 \\
7\end{array}$ & $\begin{array}{l}94.8 \\
75\end{array}$ & $\begin{array}{l}- \\
0.19 \\
9\end{array}$ & No & No & 0.731 & 0.314 & 1.99 \\
\hline 3. & $\begin{array}{l}\text { 3- } \\
\text { hydroxyanis } \\
\text { otine }\end{array}$ & $\begin{array}{l}- \\
3.70 \\
1\end{array}$ & $\begin{array}{l}84.4 \\
26\end{array}$ & $\begin{array}{l}- \\
0.25 \\
7\end{array}$ & Yes & Yes & 0.678 & $\begin{array}{l} \\
0.269\end{array}$ & $\begin{array}{l}2.31 \\
7\end{array}$ \\
\hline 4. & $\begin{array}{l}9 \text { - } \\
\text { acetamido- } \\
3,4 \\
\text { dihydropyri } \\
\text { do-(3,4-b) }\end{array}$ & $\begin{array}{l}- \\
3.12 \\
5\end{array}$ & $\begin{array}{l}94.6 \\
55\end{array}$ & $\begin{array}{l}0.12 \\
7\end{array}$ & No & No & 0.413 & $-\overline{0}-338$ & $\begin{array}{l}3.30 \\
1\end{array}$ \\
\hline
\end{tabular}




\begin{tabular}{|c|c|c|c|c|c|c|c|c|c|}
\hline & indole & & & & & & & & \\
\hline 5. & Adhatodine & $\begin{array}{l}- \\
1.27 \\
8\end{array}$ & $\begin{array}{l}75.4 \\
88\end{array}$ & $\begin{array}{l}- \\
0.17 \\
4\end{array}$ & No & No & 0.579 & 0.037 & $\begin{array}{l}2.10 \\
1\end{array}$ \\
\hline 6. & Anisotine & $\begin{array}{l}- \\
3.72 \\
8\end{array}$ & $\begin{array}{l}97.7 \\
16\end{array}$ & $\begin{array}{l}- \\
0.36 \\
8\end{array}$ & Yes & No & 0.724 & $-\overline{0} .356$ & $\begin{array}{l}2.33 \\
6\end{array}$ \\
\hline 7. & Apigenin & $-\overline{3.38}$ & $\begin{array}{l}91.5 \\
66\end{array}$ & $\begin{array}{l}- \\
0.90 \\
3\end{array}$ & No & No & 0.595 & 0.337 & $\begin{array}{l}1.97 \\
8\end{array}$ \\
\hline 8. & $\begin{array}{l}\text { Chinensinap } \\
\text { hthol methyl } \\
\text { ether }\end{array}$ & $\begin{array}{l}- \\
4.71 \\
6\end{array}$ & 100 & $\begin{array}{l}- \\
0.96 \\
1\end{array}$ & Yes & No & 0.461 & 0.307 & $\begin{array}{l}3.05 \\
3\end{array}$ \\
\hline 9. & $\begin{array}{l}\text { Deoxyvasici } \\
\text { ne }\end{array}$ & $\begin{array}{l}- \\
3.78 \\
8\end{array}$ & $\begin{array}{l}93.5 \\
74\end{array}$ & $\begin{array}{l}0.44 \\
2\end{array}$ & Yes & No & 0.125 & 0.264 & $\begin{array}{l}2.62 \\
6\end{array}$ \\
\hline $\begin{array}{l}1 \\
0 .\end{array}$ & $\begin{array}{l}\text { Deoxyvasici } \\
\text { none }\end{array}$ & $\begin{array}{l}- \\
1.72 \\
2\end{array}$ & $\begin{array}{l}99.0 \\
37\end{array}$ & $\begin{array}{l}- \\
0.07 \\
9\end{array}$ & No & No & 0.749 & $-\overline{0} 166$ & 2.07 \\
\hline $\begin{array}{l}1 \\
1 .\end{array}$ & Diphyllin & $\begin{array}{l}- \\
4.68 \\
1\end{array}$ & $\begin{array}{l}96.5 \\
04\end{array}$ & $\begin{array}{l}- \\
0.85 \\
8\end{array}$ & Yes & Yes & 0.305 & 0.137 & $\begin{array}{l}2.52 \\
4\end{array}$ \\
\hline $\begin{array}{l}1 \\
2 .\end{array}$ & $\begin{array}{l}\text { Heliobuphth } \\
\text { almin }\end{array}$ & $\begin{array}{l}- \\
4.66 \\
3\end{array}$ & 100 & $\begin{array}{l}- \\
1.11 \\
8\end{array}$ & Yes & Yes & 0.057 & 0.489 & $\begin{array}{l}2.74 \\
7\end{array}$ \\
\hline $\begin{array}{l}1 \\
3 .\end{array}$ & $\begin{array}{l}\text { Helioxanthi } \\
\text { n }\end{array}$ & $\begin{array}{l}- \\
5.03 \\
7\end{array}$ & $\begin{array}{l}98.9 \\
62\end{array}$ & $\begin{array}{l}- \\
0.05 \\
7\end{array}$ & Yes & Yes & 0.281 & 0.181 & $\begin{array}{l}2.87 \\
8\end{array}$ \\
\hline 1 & Isolariciresi & - & 74.2 & - & No & No & 0.477 & 0.531 & 2.44 \\
\hline
\end{tabular}




\begin{tabular}{|c|c|c|c|c|c|c|c|c|c|}
\hline 4. & nol & 3.04 & 9 & $\begin{array}{l}0.93 \\
9\end{array}$ & & & & & 9 \\
\hline $\begin{array}{l}1 \\
5 .\end{array}$ & Justicidin B & $\begin{array}{l}- \\
5.31 \\
1\end{array}$ & $\begin{array}{l}99.8 \\
22\end{array}$ & $\begin{array}{l}- \\
0.71 \\
6\end{array}$ & Yes & Yes & 0.35 & 0.121 & $\begin{array}{l}2.84 \\
5\end{array}$ \\
\hline $\begin{array}{l}1 \\
6 .\end{array}$ & Justicidin D & $\begin{array}{l}- \\
4.18 \\
4\end{array}$ & 100 & $\begin{array}{l}- \\
0.92 \\
6\end{array}$ & Yes & No & 0.25 & 0.339 & $\begin{array}{l}3.06 \\
6\end{array}$ \\
\hline $\begin{array}{l}1 \\
7 .\end{array}$ & Justicidin E & $\begin{array}{l}- \\
3.98 \\
9\end{array}$ & 100 & $\begin{array}{l}- \\
0.48 \\
7\end{array}$ & Yes & No & 0.221 & 0.268 & $\begin{array}{l}2.92 \\
7\end{array}$ \\
\hline $\begin{array}{l}1 \\
8 .\end{array}$ & Justicidin A & $-\overline{5.23}$ & $\begin{array}{l}98.9 \\
59\end{array}$ & $\begin{array}{l}- \\
0.95 \\
1\end{array}$ & Yes & No & 0.418 & 0.277 & $\begin{array}{l}2.92 \\
1\end{array}$ \\
\hline $\begin{array}{l}1 \\
9 .\end{array}$ & $\begin{array}{l}\text { Justiciresino } \\
1\end{array}$ & $\begin{array}{l}- \\
4.61 \\
8\end{array}$ & $\begin{array}{l}71.7 \\
91\end{array}$ & $\begin{array}{l}- \\
1.03 \\
8\end{array}$ & Yes & Yes & 0.176 & 0.276 & $\begin{array}{l}2.10 \\
9\end{array}$ \\
\hline $\begin{array}{l}2 \\
0 .\end{array}$ & Kaempferol & $\begin{array}{l}- \\
3.28 \\
2\end{array}$ & $\begin{array}{l}80.0 \\
64\end{array}$ & $\begin{array}{l}- \\
1.06 \\
5\end{array}$ & No & No & 0.496 & 0.774 & $\begin{array}{l}2.19 \\
7\end{array}$ \\
\hline $\begin{array}{l}2 \\
1 .\end{array}$ & Luteolin & $\begin{array}{l}- \\
3.29 \\
4\end{array}$ & $\begin{array}{l}82.1 \\
75\end{array}$ & $\begin{array}{l}- \\
1.14 \\
5\end{array}$ & No & Yes & 0.568 & 0.564 & $\begin{array}{l}2.45 \\
3\end{array}$ \\
\hline $\begin{array}{l}2 \\
2 .\end{array}$ & $\begin{array}{l}\text { Podophyllot } \\
\text { oxin }\end{array}$ & $\begin{array}{l}- \\
3.97 \\
1\end{array}$ & 100 & $\begin{array}{l}- \\
0.82 \\
1\end{array}$ & Yes & Yes & 0.205 & -0.45 & $\begin{array}{l}2.51 \\
2\end{array}$ \\
\hline $\begin{array}{l}2 \\
3 .\end{array}$ & Quercetin & $\begin{array}{l}- \\
2.92 \\
5\end{array}$ & $\begin{array}{l}77.2 \\
07\end{array}$ & $\begin{array}{l}- \\
1.09 \\
8\end{array}$ & No & No & 0.407 & 0.499 & $\begin{array}{l}2.47 \\
1\end{array}$ \\
\hline
\end{tabular}




\begin{tabular}{|c|c|c|c|c|c|c|c|c|c|}
\hline $\begin{array}{l}2 \\
4 .\end{array}$ & Sesamin & $\begin{array}{l}- \\
4.17 \\
3\end{array}$ & $\begin{array}{l}98.2 \\
18\end{array}$ & $\begin{array}{l}- \\
0.14 \\
7\end{array}$ & Yes & Yes & $-\overline{0}$ & 0.372 & $\begin{array}{l}2.76 \\
7\end{array}$ \\
\hline $\begin{array}{l}2 \\
5 .\end{array}$ & Taiwanin E & $\begin{array}{l}- \\
4.00 \\
7\end{array}$ & $\begin{array}{l}97.8 \\
26\end{array}$ & $\begin{array}{l}- \\
0.91 \\
3\end{array}$ & Yes & No & 0.233 & 0.261 & $\begin{array}{l}3.03 \\
5\end{array}$ \\
\hline $\begin{array}{l}2 \\
6 .\end{array}$ & $\begin{array}{l}\text { Taiwanin E } \\
\text { methyl ether }\end{array}$ & $\begin{array}{l}- \\
4.02 \\
7\end{array}$ & 100 & $\begin{array}{l}- \\
0.91 \\
7\end{array}$ & Yes & No & 0.334 & 0.445 & $\begin{array}{l}3.12 \\
5\end{array}$ \\
\hline $\begin{array}{l}2 \\
7 .\end{array}$ & $\begin{array}{l}\text { Vasicilonon } \\
\text { e }\end{array}$ & $\begin{array}{l}- \\
4.42 \\
5\end{array}$ & $\begin{array}{l}98.0 \\
54\end{array}$ & $\begin{array}{l}0.60 \\
5\end{array}$ & Yes & No & 0.789 & $-\overline{0} 113$ & $\begin{array}{l}2.23 \\
9\end{array}$ \\
\hline $\begin{array}{l}2 \\
8 .\end{array}$ & Vasicine & $\begin{array}{l}- \\
2.05 \\
2\end{array}$ & $\begin{array}{l}75.4 \\
97\end{array}$ & $\begin{array}{l}- \\
0.05 \\
9\end{array}$ & No & No & 0.591 & 0.18 & $\begin{array}{l}2.67 \\
1\end{array}$ \\
\hline $\begin{array}{l}2 \\
9 .\end{array}$ & Vasicinone & $\begin{array}{l}- \\
1.27 \\
8\end{array}$ & $\begin{array}{l}75.4 \\
88\end{array}$ & $\begin{array}{l}- \\
0.17 \\
4\end{array}$ & No & No & 0.579 & 0.037 & $\begin{array}{l}2.10 \\
1\end{array}$ \\
\hline $\begin{array}{l}3 \\
0 .\end{array}$ & Vasicoline & $\begin{array}{l}- \\
4.81 \\
5\end{array}$ & $\begin{array}{l}92.3 \\
72\end{array}$ & $\begin{array}{l}0.59 \\
6\end{array}$ & Yes & No & 0.609 & 0.127 & $\begin{array}{l}2.59 \\
2\end{array}$ \\
\hline $\begin{array}{l}3 \\
1 .\end{array}$ & $\begin{array}{l}\text { Vasicolinon } \\
\text { e }\end{array}$ & $\begin{array}{l}- \\
4.42 \\
5\end{array}$ & $\begin{array}{l}98.0 \\
54\end{array}$ & $\begin{array}{l}0.60 \\
5\end{array}$ & Yes & No & 0.789 & $\overline{-}-113$ & $\begin{array}{l}2.23 \\
9\end{array}$ \\
\hline $\begin{array}{l}3 \\
2 .\end{array}$ & Xanthoxylol & $\begin{array}{l}- \\
3.68 \\
8\end{array}$ & $\begin{array}{l}94.7 \\
56\end{array}$ & $\begin{array}{l}- \\
0.57 \\
8\end{array}$ & Yes & Yes & $\overline{-}-046$ & $\overline{-}-583$ & $\begin{array}{l}2.21 \\
1\end{array}$ \\
\hline
\end{tabular}

Table S4: Protein-ligand interaction profile of FDA approved drugs with SARS-CoV 2 Target protein 


\begin{tabular}{|c|c|c|c|c|c|c|}
\hline \multirow[b]{2}{*}{$\begin{array}{l}\mathrm{S} \\
\dot{\mathrm{N}} \\
\mathrm{O}\end{array}$} & \multirow[b]{2}{*}{ Protein } & \multirow[b]{2}{*}{$\begin{array}{l}\mathrm{P} \\
\mathrm{D} \\
\mathrm{B} \\
\mathrm{I} \\
\mathrm{D}\end{array}$} & \multirow[b]{2}{*}{$\begin{array}{l}\text { Liga } \\
\text { nd }\end{array}$} & \multirow{2}{*}{$\begin{array}{l}\text { Bin } \\
\text { din } \\
\mathrm{g} \\
\text { affi } \\
\text { nit } \\
\mathrm{y} \\
\text { (kc } \\
\mathrm{al} / \\
\mathrm{mo} \\
\mathrm{l})\end{array}$} & \multicolumn{2}{|c|}{ Amino acid residues involved and distance $(\square)$} \\
\hline & & & & & $\begin{array}{c}\text { Hydrogen } \\
\text { bonding }\end{array}$ & Hydrophobic interactions \\
\hline 1 & $\begin{array}{l}\text { Spike } \\
\text { protein }\end{array}$ & $\begin{array}{l}6 \\
\text { C } \\
\text { R } \\
\text { V }\end{array}$ & $\begin{array}{l}\text { Daru } \\
\text { navi } \\
\mathrm{r}\end{array}$ & $\begin{array}{l}- \\
1 \\
0 . \\
3\end{array}$ & $\begin{array}{l}\text { 738A TYR } \\
(3.37), 977 \mathrm{C} \\
\text { ARG (3.28), } \\
\text { 977C ARG } \\
\text { (2.46), 980A } \\
\text { THR (2.79), } \\
\text { 980C THR } \\
\text { (3.01), 980C } \\
\text { THR (2.43), } \\
\text { 980C THR } \\
(2.70), 984 \mathrm{~A} \\
\text { GLN (2.78) }\end{array}$ & $\begin{array}{l}\text { 738C TYR (3.76), 741A } \\
\text { PHE (3.23), 952C PHE } \\
\text { (3.75), 973A VAL (3.64), } \\
\text { 976A ASP (3.88), 977A } \\
\text { ARG (3.67), 980B THR } \\
(3.34), 980 C \text { THR }(3.6)\end{array}$ \\
\hline 2 & $\begin{array}{l}\text { Envelope } \\
\text { protein }\end{array}$ & $\begin{array}{l}5 \\
X \\
2 \\
9\end{array}$ & $\begin{array}{l}\text { Daru } \\
\text { navi } \\
\mathrm{r}\end{array}$ & $\begin{array}{l}- \\
1 \\
0 . \\
6\end{array}$ & & $\begin{array}{l}\text { 23D PHE (3.7), 23D PHE } \\
\text { (3.4), 26D PHE (3.82), 27D } \\
\text { LEU (3.28), 29E VAL } \\
\text { (3.46), 29E VAL (3.63), } \\
\text { 30D THR (3.95), 31D LEU } \\
\text { (3.57), 31E LEU (3.57), } \\
\text { 46D ILE (3.99), 47D VAL } \\
\text { (3.85), 57D TYR (3.79), } \\
\text { 57D TYR (3.8), 57D TYR } \\
\text { (3.68) }\end{array}$ \\
\hline 3 & $\begin{array}{l}\text { Membra } \\
\text { ne } \\
\text { protein }\end{array}$ & $\begin{array}{l}3 \\
\mathrm{I} \\
6 \\
\mathrm{G}\end{array}$ & $\begin{array}{l}\text { Daru } \\
\text { navi } \\
\mathrm{r}\end{array}$ & $\begin{array}{l}- \\
1 \\
0 . \\
2\end{array}$ & $\begin{array}{l}\text { 26B TYR (2.50), } \\
\text { 30A ASP (2.56), } \\
\text { 57B SER (3.32), } \\
\text { 58B LYS }(2.89), \\
\text { 212A GLU } \\
(2.28), 212 \mathrm{~A} \\
\text { GLU (2.36), } \\
\text { 233A THR }\end{array}$ & $\begin{array}{l}\text { 6A ARG (3.87), 27A TYR } \\
\text { (3.75), 27A TYR (3.84), } \\
\text { 27A TYR (3.98), 58B LYS } \\
\text { (3.71), 63B TYR (3.8), 63B } \\
\text { TYR (3.62), 235A PRO } \\
(3.7), 235 A \text { PRO, 241A } \\
\text { PHE (3.9), 241A PHE } \\
(3.73)\end{array}$ \\
\hline
\end{tabular}




\begin{tabular}{|c|c|c|c|c|c|c|}
\hline & & & & & $\begin{array}{l}\text { (2.41), 233A } \\
\text { THR (2.39) }\end{array}$ & \\
\hline 4 & $\begin{array}{l}\text { Main } \\
\text { protease }\end{array}$ & $\begin{array}{l}6 \\
\mathrm{~L} \\
\mathrm{U} \\
7\end{array}$ & $\begin{array}{l}\text { Saqu } \\
\text { inavi } \\
r\end{array}$ & $\begin{array}{l}- \\
8 . \\
6\end{array}$ & $\begin{array}{l}\text { 143A GLY } \\
(3.14), 144 \mathrm{~A} \\
\text { SER (2.34), } \\
\text { 145A CYS } \\
(2.59), 164 \mathrm{~A} \\
\text { HIS (2.30), } \\
\text { 166A GLU } \\
(2.36), 166 \mathrm{~A} \\
\text { GLU (3.45) }\end{array}$ & $\begin{array}{l}\text { 41A HIS (3.48), 49A MET } \\
\text { (3.81), 165A MET (3.33), } \\
\text { 166A GLU (3.95), 167A } \\
\text { LEU (3.92), 168A PRO } \\
\text { (3.53), 187A ASP (3.58), } \\
\text { 189A GLN (3.94), 189A } \\
\text { GLN (3.25) }\end{array}$ \\
\hline 5 & $\begin{array}{l}\text { Spike } \\
\text { protein } \\
\text { receptor } \\
\text { binding } \\
\text { domain }\end{array}$ & $\begin{array}{l}6 \\
M \\
0 \\
\mathrm{~J}\end{array}$ & $\begin{array}{l}\text { Hyd } \\
\text { roxy } \\
\text { chlo } \\
\text { roqu } \\
\text { ine }\end{array}$ & $\begin{array}{l}- \\
1 \\
0 . \\
1\end{array}$ & $\begin{array}{l}\text { 208A GLU } \\
(3.41), 208 \mathrm{~A} \\
\text { GLU }(2.78)\end{array}$ & $\begin{array}{l}\text { 95A LEU (3.93), 98A GLN } \\
(3.83), \text { 209A VAL (3.82), } \\
\text { 209A VAL (3.82), 210A } \\
\text { ASN (3.68), 212A VAL } \\
(3.96), 565 \text { A PRO }(3.75)\end{array}$ \\
\hline 6 & ORF 3a & $\begin{array}{l}6 \\
X \\
D \\
C\end{array}$ & $\begin{array}{l}\text { Daru } \\
\text { navi } \\
\text { r }\end{array}$ & $\begin{array}{l}- \\
9 . \\
7\end{array}$ & $\begin{array}{l}\text { 63A ILE (2.83), } \\
\text { 75A LYS (2.23), } \\
\text { 78A HIS (2.41), } \\
\text { 78A HIS (2.59), } \\
\text { 122B ARG } \\
(2.48), 126 \mathrm{~B} \\
\text { ARG (2.27), } \\
\text { 142B ASP } \\
\text { (3.02), 206B } \\
\text { TYR (2.76) }\end{array}$ & $\begin{array}{l}\text { 61A LYS (3.65), 122B } \\
\text { ARG (3.97), 142A ASP } \\
(3.64), 206 B \text { TYR }(3.66)\end{array}$ \\
\hline 7 & $\begin{array}{l}\text { Non } \\
\text { structural } \\
\text { protein } 3\end{array}$ & $\begin{array}{l}6 \\
W \\
X \\
D\end{array}$ & $\begin{array}{l}\text { Daru } \\
\text { navi } \\
\mathrm{r}\end{array}$ & $\begin{array}{l}- \\
8 . \\
3\end{array}$ & $\begin{array}{l}\text { 157A ASP } \\
(2.55)\end{array}$ & $\begin{array}{l}\text { 23A ILE (3.19), 49A VAL } \\
\text { (3.69), 52A ALA (3.49), } \\
\text { 126A (LEU), 131A ILE } \\
\text { (3.53), 132A PHE (3.69), } \\
\text { 155A VAL (3.72), 156A } \\
\text { PHE (3.43), 160A LEU } \\
(3.41), 160 A \text { LEU (3.76) }\end{array}$ \\
\hline 8 & $\begin{array}{l}\text { Non } \\
\text { structural } \\
\text { protein } 9\end{array}$ & $\begin{array}{l}2 \\
\text { G } \\
9 \\
T\end{array}$ & $\begin{array}{l}\text { Atov } \\
\text { aquo } \\
\text { ne }\end{array}$ & $\begin{array}{l}- \\
8 . \\
8\end{array}$ & 41A VAL (2.48) & $\begin{array}{l}\text { 39A ARG (3.92), 40A PHE } \\
\text { (3.52), 40A PHE (3.33), } \\
\text { 41A VAL (3.7), 41A VAL } \\
\text { (3.98), 56A PHE (3.95), } \\
\text { 91A ILE (3.59) }\end{array}$ \\
\hline
\end{tabular}




\begin{tabular}{|c|c|c|c|c|c|c|}
\hline 9 & $\begin{array}{l}\text { Non } \\
\text { structural } \\
\text { protein } \\
10\end{array}$ & $\begin{array}{l}6 \\
\mathrm{~V} \\
\mathrm{~W} \\
\mathrm{~W}\end{array}$ & $\begin{array}{l}\text { Saqu } \\
\text { inavi } \\
\mathrm{r}\end{array}$ & $\begin{array}{l}- \\
1 \\
0 . \\
4\end{array}$ & $\begin{array}{l}\text { 94E GLY (3.18), } \\
\text { 96F TYR (3.27) }\end{array}$ & $\begin{array}{l}\text { 21L VAL (3.4), 23L PRO } \\
\text { (3.84), 42E VAL (3.64), } \\
\text { 57F VAL (3.69), 58F THR } \\
\text { (3.95), 76L TYR (3.76), } \\
\text { 76L TYR (3.73), 81L ILE } \\
\text { (3.64), 84L PRO (3.56), } \\
\text { 96E TYR (3.93), 96F TYR } \\
\text { (3.66) }\end{array}$ \\
\hline $\begin{array}{l}1 \\
0\end{array}$ & $\begin{array}{l}\text { Non } \\
\text { structural } \\
\text { protein } \\
15\end{array}$ & $\begin{array}{l}6 \\
V \\
X \\
S\end{array}$ & $\begin{array}{l}\text { Iver } \\
\text { mect } \\
\text { in }\end{array}$ & $\begin{array}{l}- \\
1 \\
0 . \\
6\end{array}$ & $\begin{array}{l}\text { 46A ASN (3.32), } \\
\text { 46B ASN (2.57), } \\
\text { 52A VAL (2.19) }\end{array}$ & - \\
\hline
\end{tabular}

